\title{
Bilateral Syringeal Coupling During Phonation of a Songbird
}

\author{
Stephen Nowicki ${ }^{1}$ and Robert R. Capranica \\ Section of Neurobiology and Behavior, Cornell University, Ithaca, New York 14853
}

\begin{abstract}
The syrinx of oscine birds ("true songbirds") is a double vocal organ, and each side has generally been presumed to function independently under separate neural control during phonation. A significant counterexample is demonstrated here in the production of a common vocalization by the black-capped chickadee (Parus atricapillus), in which the 2 acoustic sources of the syrinx interact in a nonlinear fashion. The chickadee produces a sound with multiple frequency components that superficially resemble harmonics. An analysis of vocal production after unilateral and bilateral syringeal denervation shows instead that these frequency components are sum and difference frequencies, or heterodyne frequencies, resulting from cross-modulation between the 2 syringeal sides. A limited form of this bilateral coupling may be achieved after unilateral denervation of either syringeal side but not after bilateral denervation. Unilaterally denervated birds are capable of significant improvement in coupling after $10 \mathrm{~d}$, ton short a period for neural regrowth. These results suggest that coupling arises from a passive physical interaction between the 2 syringeal sources which is activated or regulated in some fashion by neural control from either side.
\end{abstract}

The vocal organ, or syrinx, of songbirds is a double organ. Located at the junction of the primary bronchi, it possesses a symmetrical pair of tympaniform membranes, muscles, and supporting structures thought to be involved in the generation of sound, with 1 set in the lumen of each bronchus (Brackenbury, 1982; Gaunt and Gaunt, 1985; Greenewalt, 1968; Nottebohm, 1975). The organ is also bilaterally innervated, each side receiving the ipsilateral tracheosyringeal branch of the XIIth cranial (hypoglussal) nerve (Arnold, 1982; Nottebohm, 1971, 1980). Although early anatomists recognized the uniqueness of this morphological peculiarity, they were unwilling to postulate that a bird could have 2 independent sound sources and assumed instead that the 2 sides of the syrinx always acted in unison (e.g., Häcker, 1900; Savart, 1826). The development of the sound spectrograph, however, led to the discovery that birds can simultaneously produce 2 sounds that are not harmonically related (Borror and Reese, 1956; Potter et al., 1947), suggesting that the 2 syringeal sides act independently. Greenewalt (1968) elaborated this point by using frequency filters to isolate the presumptive 2 voices in the recorded songs of a large number of avian species.

\footnotetext{
Reccived Mar. 20, 1986; revised Junc 23, 1986; accepted July 1, 1986.

We thank C. Clark, M. Konishi, P. Marler, D. Nelson, S. Peters, and an anonymous reviewer for comments on the manuscript, and J. Conner for technical assistance. This work was supported by grants from Sigma Xi, the National Academy of Sciences, and the American Ornithologist's Union; by A. D. White and H. Sage Fellowships and NIMH Predoctoral Traineeship 5 T32 MH 15793-05 (to S.N.); and NIH Grant NS-09244 (to R.R.C.).

Correspondence should be addressed to Dr. Stephen Nowicki, The Rockefeller University, Field Research Center, RR No. 2, Box 38B, Tyrrel Road, Millbrook, NY 12545

' Present address: The Rockefeller University, Field Research Center, Tyrrel Road, Millbrook, NY 12545.
}

Copyright $@ 1986$ Society for Neuroscience $0270-6474 / 86 / 123595-16 \$ 02.00 / 0$
Nottebohm $(1977,1980)$ gave further support to the "twovoice theory" through physiological experimentation on the control of sound production in songbirds. When the hypoglossal nerve leading to the left side of a bird's syrinx was sectioned, he discovered that a majority of the syllables dropped out of the postoperative songs. Sectioning the right side alone had relatively little effect on most of the syllables but caused a few syllables (presumably those that were unaffected by a left hypoglossal section) to drop out. These results suggested that each syringeal half performs independently in the production of its subset of the acoustic elements that make up a complete song, and that the neural control of the syrinx is lateralized, with the left side dominant. Similar results have been obtained from several species, including the chaffinch (Fringilla coelebs), the white-throated sparrow (Zonotrichia albicollis), the whitecrowned sparrow ( $Z$. leucophrys), the canary (Serinus canarius), and the Java sparrow (Padda oryzivora) (Lemon, 1973; Nottebohm, 1971; Nottebohm and Nottebohm, 1976; Seller, 1979).

While it seems safe to conclude, on the basis of these studies, that the 2 acoustic sources in a songbird's syrinx sometimes act independently, there is no evidence that they cannot, at other times, be coupled. Given the small size of the organ, the close proximity of the 2 sides, and the many physical connections between them, it would be surprising if the 2 syringeal sides never operated in some connected fashion. In this report we present research, previously introduced in a preliminary report (Nowicki and Capranica, 1986), that demonstrates that in the production of the "chick-a-dee" or "scold" call of the blackcapped chickadee (Parus atricapillus), phonation results from a cooperative interaction between the 2 sides of the syrinx.

The "chick-a-dee" call, the onomatopoetic origin of the species' common name, was analyzed in Greenewalt's (1968) treatise on the production of birdsong, in which the "dee" syllable was used as an example of an avian source-generated harmonic sound. In the frequency domain, this syllable appears as a series of 12 20 evenly spaced spectral components, which could conceivably be the higher harmonics of a missing fundamental. The frequencies of these components, however, are not necessarily an integral multiple of the spacing between them, thus yielding an ambiguous value for a fundamental frequency in many cascs (Nowicki and Capranica, 1986). In these cases the sound could not be produced as a true harmonic series, which suggests that an alternative mechanism of production must be involved.

Previous studies have concentrated on the deletion of entire notes or syllables of a song as a consequence of unilateral denervation of the syrinx (Arnold and Bottjer, 1985; Nottebohm, 1980). These sounds are composed primarily of pure tones (or "whistles") presumed to arise from the action of only 1 side of the syrinx. Nottebohm (1972) also analyzed calls and subsong syllables of the chaffinch, which are often composed of 2 temporally overlapping acoustic elements thought to arise from the independent action of the 2 syringeal halves under separate neural control. The "dee" syllable of the "chick-a-dee" call is not a pure-tone "whistle," nor is it composed of elements that can readily be attributed to 2 separate "voices." Greenewalt 


\begin{tabular}{|c|c|c|c|c|c|c|}
\hline Bird & $\begin{array}{l}\text { NW } \\
\text { (Female) }^{a}\end{array}$ & $\begin{array}{l}\text { WP } \\
\text { (Male) }\end{array}$ & $\begin{array}{l}\text { KR } \\
\text { (Female) }\end{array}$ & $\begin{array}{l}\mathrm{TE} \\
\text { (Male) }\end{array}$ & $\begin{array}{l}\text { RY } \\
\text { (Female) }\end{array}$ & $\begin{array}{l}\text { GL } \\
\text { (Female) }\end{array}$ \\
\hline Intact recording & $3 / 24 / 81$ & $3 / 28 / 81$ & $4 / 15 / 81$ & $3 / 28 / 81$ & $3 / 28 / 81$ & $4 / 15 / 81$ \\
\hline Unilateral nerve section & $\begin{array}{l}\text { Left } \\
3 / 25 / 81\end{array}$ & $\begin{array}{l}\text { Left } \\
3 / 30 / 81\end{array}$ & $\begin{array}{l}\text { Left } \\
4 / 15 / 81\end{array}$ & $\begin{array}{l}\text { Right } \\
3 / 30 / 81\end{array}$ & $\begin{array}{l}\text { Right } \\
4 / 15 / 81\end{array}$ & $\begin{array}{l}\text { Right } \\
4 / 15 / 81\end{array}$ \\
\hline Postoperative recordings & $\begin{array}{l}3 / 28 / 81 \\
(3 \mathrm{~d}) \\
4 / 4 / 81 \\
(10 \mathrm{~d})\end{array}$ & $\begin{array}{l}4 / 26 / 81 \\
(27 \mathrm{~d}) \\
4 / 30 / 81 \\
(3 \mathrm{~d})^{b} \\
5 / 7 / 81 \\
(10 \mathrm{~d})\end{array}$ & $\begin{array}{l}4 / 19 / 81 \\
(4 d)\end{array}$ & $\begin{array}{l}4 / 2 / 81 \\
(3 \mathrm{~d}) \\
4 / 10 / 81 \\
(11 \mathrm{~d})\end{array}$ & $\begin{array}{l}4 / 19 / 81 \\
(4 \mathrm{~d}) \\
4 / 26 / 81 \\
(11 \mathrm{~d})\end{array}$ & $\begin{array}{l}4 / 19 / 81 \\
(4 \mathrm{~d}) \\
4 / 25 / 81 \\
(10 \mathrm{~d})\end{array}$ \\
\hline $\begin{array}{l}\text { Bilateral nerve section } \\
\text { Postoperative recordings }\end{array}$ & $\begin{array}{l}4 / 13 / 81 \\
4 / 26 / 81 \\
(13 \mathrm{~d}) \\
5 / 7 / 81 \\
(24 \mathrm{~d}) \\
5 / 14 / 81 \\
(31 \mathrm{~d})\end{array}$ & $5 / 11 / 81$ & $5 / 4 / 81$ & $\begin{array}{l}4 / 10 / 81 \\
4 / 12 / 81 \\
(2 \mathrm{~d})\end{array}$ & $\begin{array}{l}5 / 4 / 81 \\
5 / 7 / 81 \\
(3 \mathrm{~d})\end{array}$ & $5 / 4 / 81$ \\
\hline
\end{tabular}

\footnotetext{
${ }^{a}$ Sex determined by laparotomy or dissection upon completion of the experiment.

${ }^{b}$ Vocal recordings of WP were not obtained until $27 \mathrm{~d}$ after nerve section, by which time some vocal recovery had apparently occurred. The left nerve was resectioned on $4 / 27 / 81$. See text for details.

c The previously cut side was examined for neural regrowth, then resectioned along with the previously uncut side.

${ }^{d}$ Three birds ceased calling immediately after bilateral section, and 2 ceased calling within a few days. See text for details.
}

(1968) did not address the possible involvement of 2 syringeal acoustic sources in his discussion of the production of harmoniclike sounds. It was therefore of interest to evaluate the potential contribution of the 2 sources to the production of the "dee" syllable and the nature of their peripheral neural control. Contrary to predictions based on earlier work, the data presented here demonstrate that the 2 syringeal halves do not function independently in the production of this sound. Instead, both sides of the syrinx act together, under bilateral neural control, in a way not previously described for oscine phonation.

\section{Materials and Methods}

\section{Animals and surgical procedures}

Black-capped chickadees ( $P$. atricapillus) were trapped as adults in the vicinity of Ithaca, New York. The birds were maintained in a large indoor free-flight aviary, kept on a natural light cycle, and fed unlimited quantities of sunflower seeds and water, supplemented with mealworms and a vitamin-enriched diet.

Animals were anesthetized with sodium pentathol (Nembutal; Abbott Laboratories). Either the right or left tracheosyringealis (ts) nerve was cut by removing a $1 \mathrm{~mm}$ section at a point approximately $2 \mathrm{~mm}$ below the main trunk of the XIIth cranial (hypoglossal) nerve. Sectioning this descending nerve branch has the same effect on syringeal function as cutting the hypoglossal roots above the anastomosis of the Xth and XIIth cranial nerves (Nottebohm and Nottebohm, 1976). While most of the animals vocalized soon after recovery from the anesthesia $(1 / 2$ to $1 \mathrm{hr}$ postoperative), each was allowed to recover for at least $2 \mathrm{~d}$ before any tape recordings of its sounds were made.

Each bird was subjected to surgery a second time between 11 and 19 $\mathrm{d}$ after the first surgery, both to inspect the previously cut side and to section the remaining intact side and thus achieve bilateral denervation of the syrinx. Bilaterally denervated birds were reoperated upon at least once more to inspect for nerve regeneration. Several birds were also subject to postmortem dissection. Records of experimental animals, their surgical histories, and their dates of vocal recording are shown in Table 1.

\section{Acoustic recording and analysis techniques}

Vocal signals were recorded with a Nagra $4.2 \mathrm{~L}$ tape recorder at $19 \mathrm{~cm} /$ sec and a Sennheiser MKH 415T cardioid microphone under free-field conditions in an outdoor aviary. The frequency response of this recording system was virtually flat well beyond the range of interest, 100 $10,000 \mathrm{~Hz}$. Each bird was recorded once before and at least twice after surgery (Table 1). Some birds were maintained for up to 2 months after bilateral denervation in order to evaluate possible recovery of function, and their vocal signals were recorded periodically during this time (Table 1).

Recordings were examined in the frequency domain using a Kay sonagraph set (Model 7029A) at a bandwidth of $80-8000 \mathrm{~Hz}$ in both the narrow-band filter mode (temporal resolution, $22 \mathrm{msec}$; frequency resolution, $45 \mathrm{~Hz}$ ) and the wide-band filter mode (temporal resolution, $3.3 \mathrm{msec}$; frequency resolution, $300 \mathrm{~Hz}$ ). More accurate digital spectral sections were obtained using a Mini-Ubiquitous FFT spectral analyzer (Nicolet Scientific Corp., Model 444A) set at a bandwidth of 0-5000 $\mathrm{Hz}$. Spectra were calculated from the middle of each syllable, triggered by recordings played at half-speed, and yielded an effective analysis bandwidth of $0-10,000 \mathrm{~Hz}$, with a sample duration of $40 \mathrm{msec}$ and frequency resolution of $25 \mathrm{~Hz}$.

Signals were examined in the time domain using both the timeamplitude display of the Mini-Ubiquitous to examine waveforms of particular spectral sections and a Textronix 564 storage oscilloscope. Permanent oscillographic records of longer signal durations werc made using a Grass linagraph camera.

\section{Results}

\section{The "dee" syllable of intact animals}

The "chick-a-dee" call (Fig. 1A) comprises a variable number and arrangement of introductory syllables-generally simple FM sweeps - followed by a variable number of "dee" syllables (Mammen and Nowicki, 1981). The introductory syllables will not be considered in detail in this report. The "dee" syllables last approximately $150 \mathrm{msec}$ and are composed of a series of 12-20 temporally overlapping spectral components, evenly spaced at about $400 \mathrm{~Hz}$ (Fig. 1B). The spacing of components can vary from roughly $350 \mathrm{~Hz}$ to $450 \mathrm{~Hz}$ among different calls, but the interval remains constant within any single spectrum. This variation in spectral structure of "dees," both from different individuals and from the same individual at different times, has been shown to be a behaviorally relevant carrier of information, modifiable through learning, concerning social affilia- 

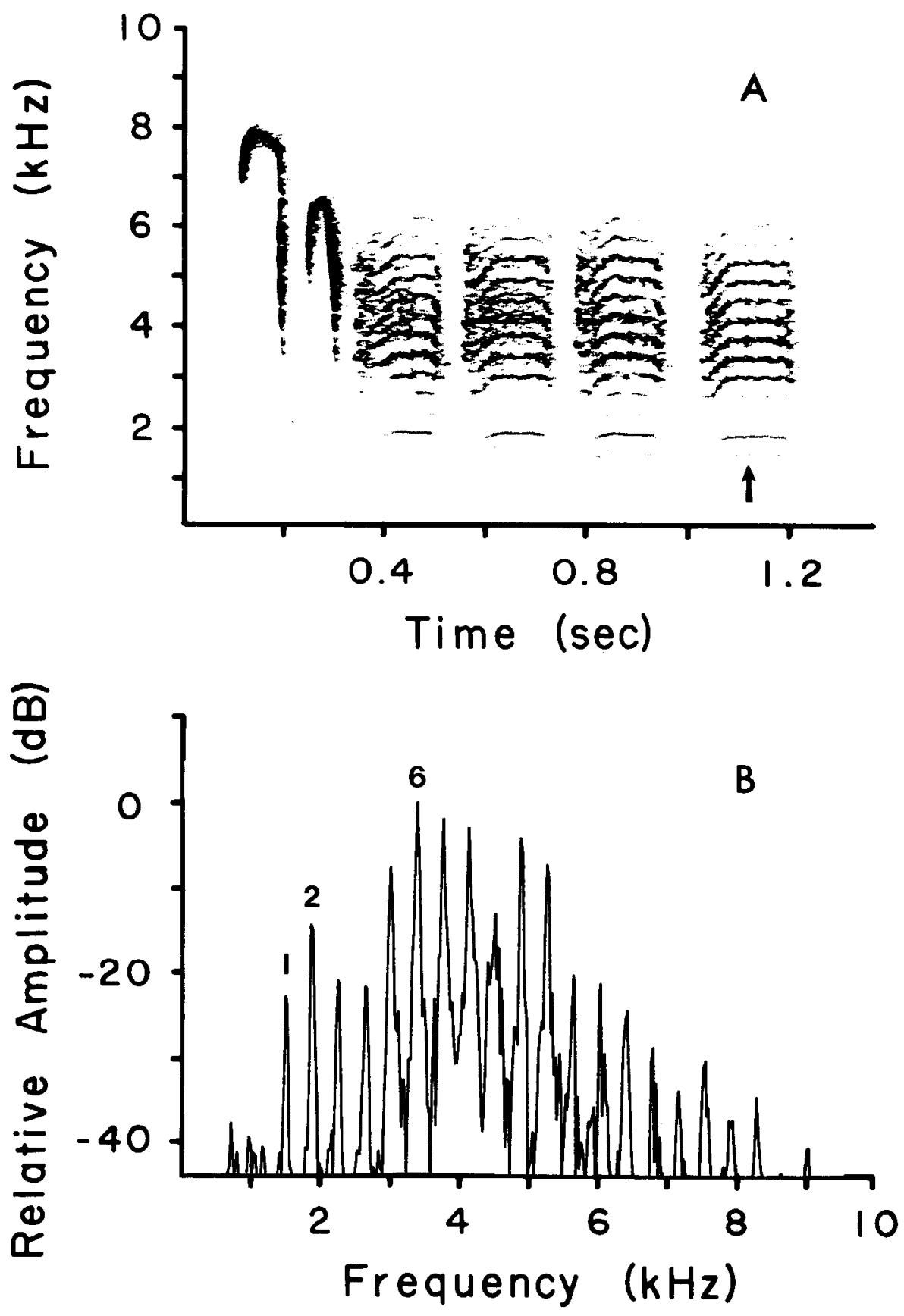

Figure 1. A, Narrow-band sonagram (temporal resolution, $22 \mathrm{msec}$; frequency resolution, $45 \mathrm{~Hz}$ ) of a normal "chick-a-dee" call with 2 introductory and 4 "dee" syllables. $B$, Amplitude spectrum for a $40 \mathrm{msec}$ section of a "dee" (as marked) using a Nicolet FFT analyzer (frequency resolution, $25 \mathrm{~Hz}$ ). Spectral components are measured in decibels $(\mathrm{dB})$ relative to the component of maximum amplitude, which is assigned $0 \mathrm{~dB}$. The first 2 components with significant energy and the component of maximum amplitude are numbered as described in the text. (Reprinted with permission from Nowicki and Capranica. Copyright 1986 by the AAAS.)

tion (Mammen and Nowicki, 1981; Nowicki, 1983, 1985).

The orderly spectral structure of the "dee" bears a strong resemblance to a harmonic series with a fundamental frequency of about $400 \mathrm{~Hz}$ (Greenewalt, 1968), but the lowest-frequency spectral component that consistently displays significant energy invariably occurs at what would be the 4th harmonic of such a series, or about $1600 \mathrm{~Hz}$ (Nowicki and Capranica, 1986) (Figs. $1 B ; 2, A-C)$. Occasionally 1 component, and more rarely 2 , will appear below this first component, but at a greatly reduced amplitude. The next highest frequency component (about 2000 $\mathrm{Hz}$ ) is also invariably of strong amplitude.

The spacing of higher-frequency components remains constant at the interval between these first 2 spectral components (labeled 1 and 2 ; Figs. $1 B ; 2, A-C$ ). The relative amplitudes of these components vary, but there is generally an increase in the cnergy of successive peaks up to 5-8 (about $3000-4000 \mathrm{~Hz}$ ), followed by a decrease. The maximum energy sometimes occurs as low as at the 4th component or as high as at the 11 th component.

Spectra of different "dees" also vary in the degree to which their frequency components are sharply defined. Most spectra have remarkably sharp peaks, with little or no noise (e.g., Fig. $2, A, B)$, while others are less well-defined, with the appearance of irregular (noisy) components spread throughout the spectrum at lower amplitude (e.g., Fig. 2C). In the time domain, the waveform of the "dee" often appears as a series of pronounced amplitude fluctuations (Fig. $2, D, F$ ). In such cases, the amplitude pcriodicity always corresponds exactly to the frequency interval between successive spectral components (i.e., about 400 $\mathrm{Hz}$ ).

\section{Effects of unilateral tracheosyringealis section}

The effects of sectioning either right or left ts nerves are similar. In vocal recordings made $3 \mathrm{~d}$ after sectioning either side, the 
Figure 2. $A-C$, Amplitude spectra of 3 representative syllables produced by normal animals $(A$, bird NW; $B$, $C$, bird TE). Components numbered as in Figure $1 B . D-F$, Temporal waveforms corresponding to spectral sections $A-C$, respectively.

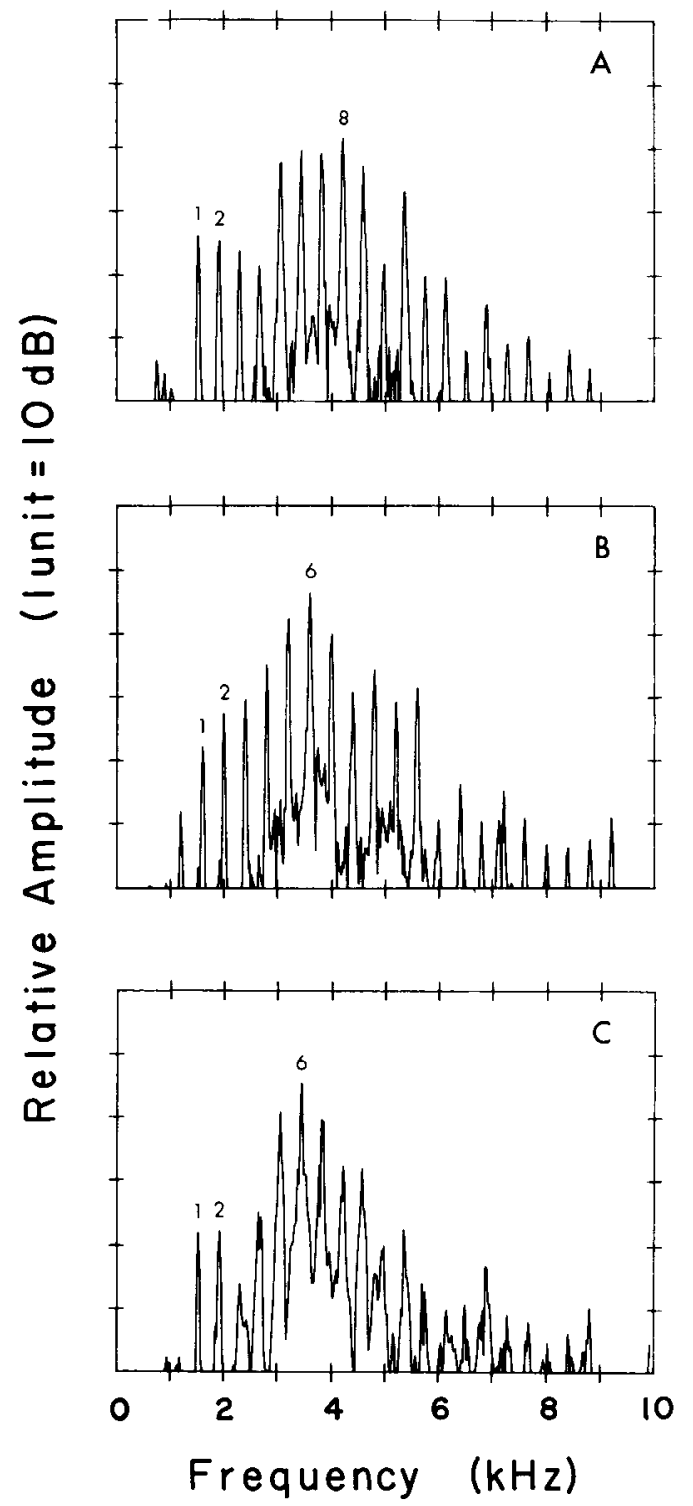

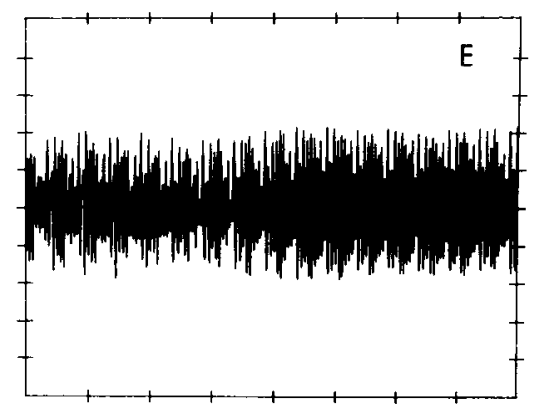

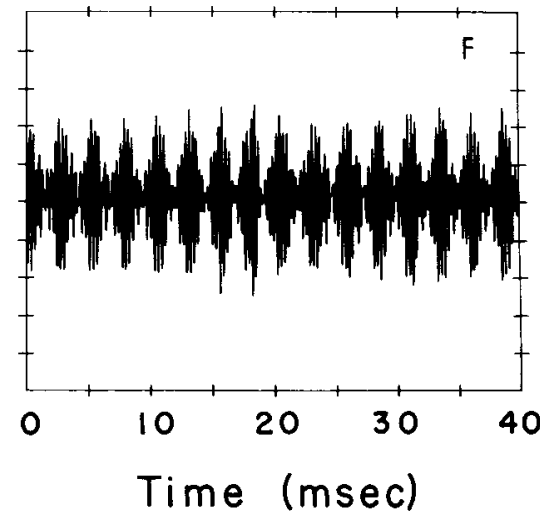

"dee" syllables lose their evenly spaced spectral structure and appear as very noisy signals with relatively few delineated spectral components, as seen in sonagrams (Fig. 3). The overall gross temporal characteristics of the call remain unchanged.

A clearer view of the spectral characteristics of postoperative signals is seen in individual spectra (Figs. 4, 5). Here it becomes apparent that there is some definite spectral structure and that the strongest spectral components are harmonics of a fundamental frequency in the range of $1500-2000 \mathrm{~Hz}$. Two or more higher harmonics are apparent in each case. These harmonics are accompanied by broadband, nonharmonic noise, with maximum energy in the region of $3000-5000 \mathrm{~Hz}$. Other sharply defined extraneous frequency components may be present. The harmonic components in postoperative signals remain constant for any bird, but these extraneous components are not predictable and may differ even in 2 consecutive "dee" syllables produced in the same call (Fig. 6).

While the results of denervating either side of the syrinx are qualitatively similar, the frequency of the fundamental in a postoperative signal depends on which side is cut. If the right side is sectioned, the fundamental frequency occurs at about 1400$1600 \mathrm{~Hz}$ (Fig. 4), while if the left side is cut, the fundamental occurs at $1800-2000 \mathrm{~Hz}$ (Fig. 5). These fundamental frequencies correspond to the frequencies of component 1 (if the right side is cut) and of component 2 (if the left side is cut) of the preoperative signals (Fig. 7).

Thus, sectioning the right ts nerve eliminates most of the spectral structure of the normal signal, but the spectral peak corresponding to component 1 of the normal signal (1400-1600 $\mathrm{Hz}$ ) remains intact and is accompanied by 2 or more higher harmonics (Figs. 4, 7). A spectral component that roughly corresponds to component 2 of the intact signal is sometimes also apparent after right ts section (Fig. $4, A, B$ ), but at a much reduced amplitude. The frequency of component 1 in the postoperative signal remains virtually the same as in the preoperative case for an individual bird (operationally defined as $\pm 5 \%$, representing, for example, an $80 \mathrm{~Hz}$ deviation from a value of $1600 \mathrm{~Hz}$ ). The frequency component corresponding to component 2, however, if it is present at all, may be shifted by several hundred hertz. This second spectral component is usually not as sharply defined as the first component (e.g., Fig. 4A). Furthermore, the amplitude, frequency, and sharpness of component 2 , if apparent, vary greatly from syllable to syllable, while component 1 and its harmonics remain relatively constant in postoperative signals. If the left ts nerve is cut, the spectral component corresponding to component 2 of the normal signal 


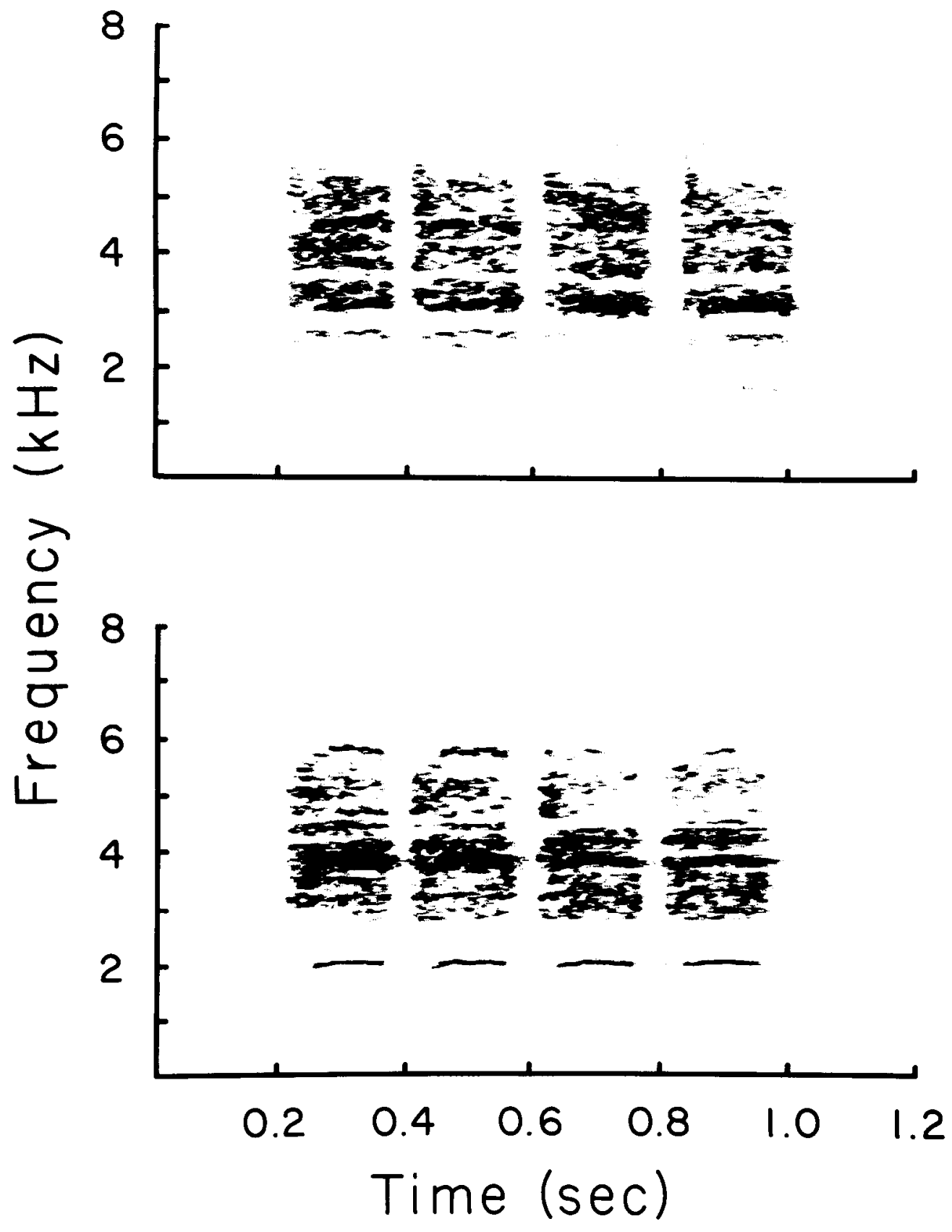

Figure 3. Narrow-band $(45 \mathrm{~Hz})$ sonagrams of "chick-a-dee" calls produced after unilateral tracheosyringealis (ts) nerve section. Top, Call made $4 \mathrm{~d}$ after section of the right ts nerve (bird GL). Bottom, Call made $3 \mathrm{~d}$ after section of the left ts nerve (bird NW). Both calls include 4 "dee" syllables and no introductory syllables.
(1600-2000 Hz) predominates with its harmonics (Figs. 5, 7). The spectral component corresponding to component 1 is often present as well and is well defined (in contrast to component 2 in the right nerve section case). The frequency of this spectral peak, however, is more variable than that of component 2 in this case, and its amplitude is reduced, but the component is usually not absent altogether.

In summary, sectioning the right side results in component 1 and its harmonics' dominating the signal, while sectioning the left side causes component 2 and its harmonics to be dominant. In either case, the other component ( 2 in the case of a right nerve section, 1 in the case of a left nerve section) may still be present, but it is less stable from signal to signal and its amplitude is much reduced. If this weaker component has sufficient amplitude, it may also display higher harmonics, although never as great in amplitude or as sharply defined as those of the dominant spectral component. This weaker fundamental component is more commonly observed in the case of a left nerve section (e.g., Fig. 5, $A, B$ ).

Some of the nonconstant extraneous spectral components in postoperative signals do not correspond to the harmonics of either component 1 or 2 , but nevertheless they may be spaced at regular intervals away from harmonic components. Their spacing corresponds to the frequency difference between components 1 and 2 if both occur (e.g., Figs. $4 A ; 5, A, C$ ). Note that this difference frequency may be quite unlike that observed in preoperative cases, owing to postoperative shifts in the frequency of the wcaker component.

In the time domain, postoperative signals (for both right- and left-operated birds) are characterized by their irregular waveforms, compared with preoperative signals (compare Fig. 2, $D$ $F$ with Figs. $4, D-F$ and $5, D-F$ ). No consistent differences are apparent in the waveforms from right- and left-sectioned birds. Occasionally, amplitude fluctuations display periodicity in the 
Figure 4. $A-C$, Representative amplitude spectra or "dee" syllables produced by 3 different birds 3 or $4 \mathrm{~d}$ after section of the right ts nerve $(A$, bird RY; $B$, bird GL; $C$, bird TE). The spectral components corresponding to component 1 of the intact signal and 2 of its harmonics are marked with arrows. Higher harmonics are also discernible. See text for details. $D-F$, Temporal waveforms corresponding to spectral sections $A-C$, respectively.

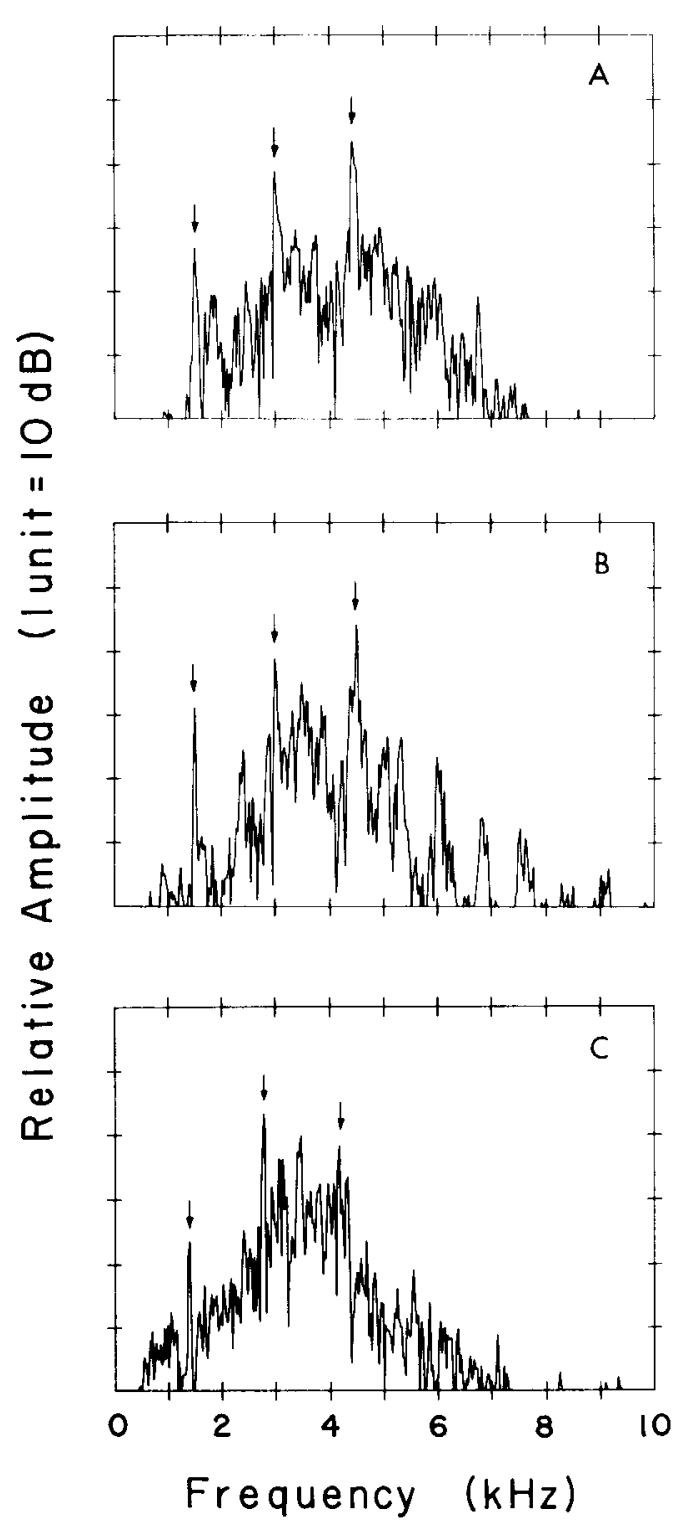

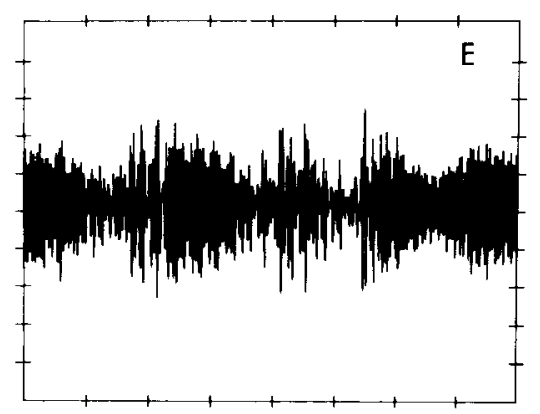

range of $400 \mathrm{~Hz}$ (e.g., Fig. $5 E$ ), but never with as much regularity as is seen in normal signals.

\section{Recovery after unilateral tracheosyringealis sections}

Noticeable changes in postoperative signals occurred within 10 $\mathrm{d}$ after right or left unilateral ts nerve sections. In some cases, there was a further decrease in amplitude or a complete disappearance of the weaker of the first 2 spectral components (e.g., compare Figs. $8 A$ and $5 A$ ). This change was accompanied by the replacement of nonharmonic components with broadband noise. In one unusual case, a bird with a right ts nerve section was able to completely silence the noise as well (Fig. 8C). This effect was observed only rarely, and in the same recording session the bird produced mostly noisier signals (compare Fig. 8 , $B$ and $C$ ).

In contrast to the examples just given, a more usual change after $10 \mathrm{~d}$ involved an increase in the amplitude of the weaker fundamental component (Fig. 9), although the frequency of this component remained highly variable. More noticeably, this change entailed a proliferation of sharply defined spectral peaks, spaced at intervals corresponding to the interval between the 1 st and 2 nd fundamental components (compare Figs. $9 A$ and $5 B, 9 B$ and $4 A$, and $9 C$ and $4 C$ ). These spectral peaks were clustered around the harmonics of the dominant fundamental component (e.g., Fig. 9, $B, C$ ). In all cases, the new components were regularly spaced at the difference interval between components 1 and 2 . Broadband noise was reduced but was not eliminated entirely. In a few cases, the spectrum of the postoperative signal bore a resemblance to that of a normal signal (Fig. 9C).

One bird, whose left ts was sectioned, was recorded 4 weeks later. Its signals were in many cases similar to preoperative signals (Fig. 10A). Although the spectral components were not as sharply defined, the distribution of energy in those components was similar to that of normal birds and there was relatively little broadband noise present. The animal also continued to produce signals that were at least as unstructured as those recorded $3 \mathrm{~d}$ postoperatively (Fig. 10B). Surgical examination of this animal revealed a large neuroma on the cut end of the tracheosyringealis, with several processes extending distally. The animal ceased to produce such normal-appearing signals after resection of the nerve proximal to the first cut.

\section{Effects of bilateral tracheosyringealis section}

The most obvious result of bilaterally sectioning the tracheosyringealis nerves was that the animals produced a wheezing 


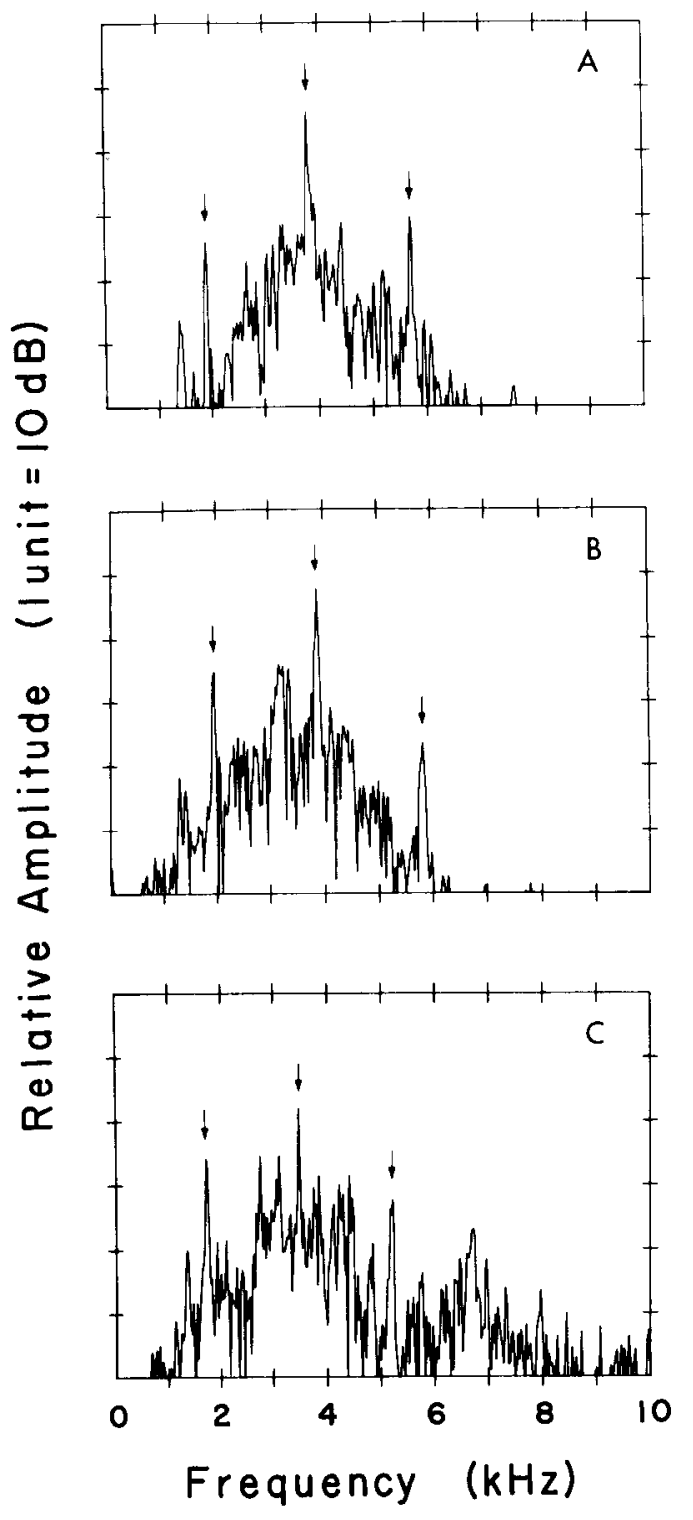

sound with every respiratory cycle when excited, as has previously been reported for other species (e.g., Nottebohm, 1971). These sounds increased in intensity as the animals became more excited and were presumably breathing harder. Each "wheeze" was composed of broadband noise that extended beyond 16,000 $\mathrm{Hz}$, a much higher frequency than occurs in any other sound made by chickadces (Fig. 11A). Well-defined spectral components sometimes occurred near the frequencies of components 1 and 2 of a normal "dee" syllable. On rare occasions, higher harmonics of these components were discernible as well. As expected, the waveforms of these wheezy sounds were highly irregular (Fig. 11B).

Chickadees are much less likely to produce the "chick-a-dee" call after bilateral nerve section. A few examples were recorded, however, and these could easily be distinguished from the wheezing sound of respiration by their increased acoustic intensity and especially by their gross temporal pattern, which remained the same as the call of an intact bird. This pattern, and the general lack of an organized spectral structure, is evident in sonagrams of calls after bilateral section (Fig. 12). Note that the introductory syllables, usually pure-tone FM sweeps, have a spectral appearance that is similar to that of the "dee" syllables but differ in their frequency range and bandwidth. Occasionally a bird produced a signal with the first and second fundamental components apparent (Fig. 13C). The waveforms of these signals were always highly irregular (Fig. $13, D-F$ ).

\section{Recovery after bilateral tracheosyringealis section}

One bird (NW) remained vocal for an extended time following bilateral section and was recorded up to $4 \frac{1}{2}$ wecks latcr. No differences were observed between this bird's vocalizations, made $13 \mathrm{~d}$ postoperatively, and those recorded from other birds 2 or $3 \mathrm{~d}$ postoperatively (Fig. 13). After $31 \mathrm{~d}$, however, the bird sometimes produced signals with structured and noise-free spectra (Fig. 14A). These signals differed from normal preoperative signals in having a much wider spacing between successive spectral components (about $525 \mathrm{~Hz}$ ) and a limited number of these components. On the same day, this bird also produced much noisier signals, typical of bilateral postoperative signals, although spectral components corresponding to components 1 and 2 of normal signals were still apparent (Fig. 14B).

\section{Discussion}

Neither side of the chickadee's syrinx, after denervation of the contralateral side, can correctly produce the "dee" syllable of the "chick-a-dee" call (Figs. 4,5 ). Nor do 2 postoperative sig- 


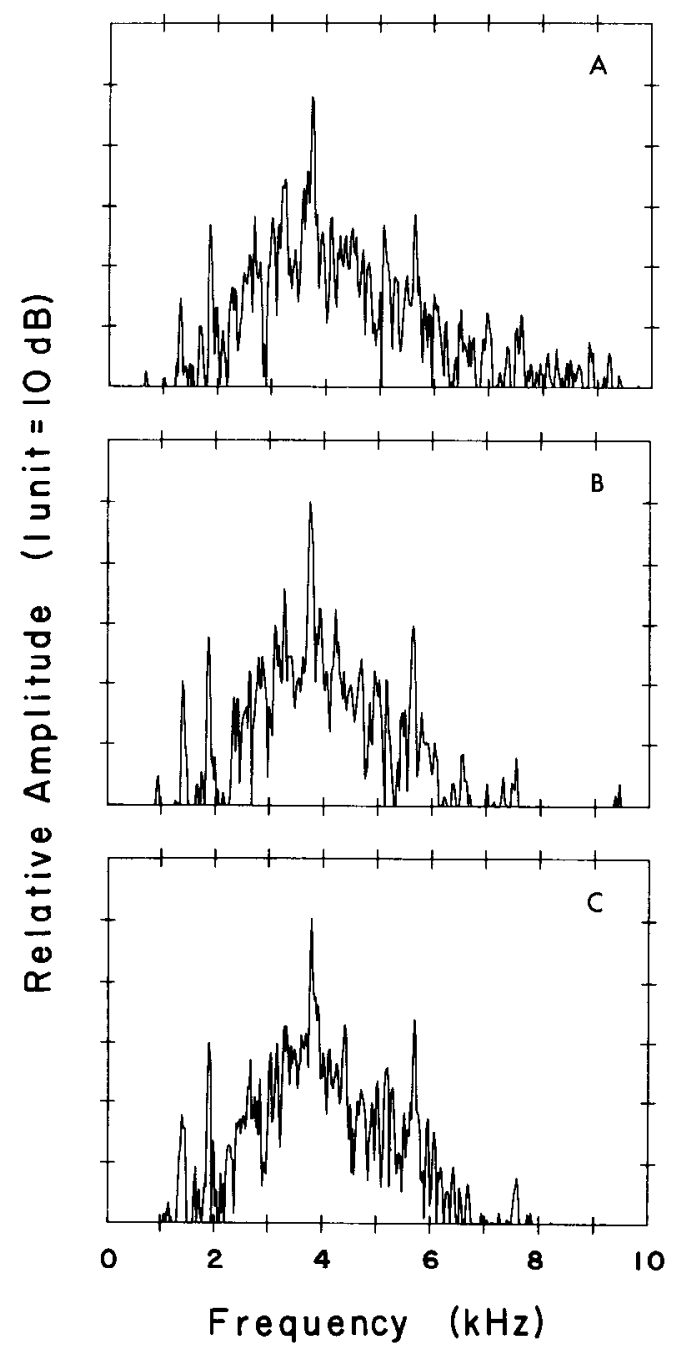

Figure 6. $A-C$, Amplitude spectra of 3 "dee" syllables produced by a single bird $3 \mathrm{~d}$ after section of the left ts nerve (bird NW) illustrating the constancy of the dominant harmonic components in postoperative signals of the same bird and the inconstancy of extraneous components. $B, C$, Spectra of 2 successive "dees" in the same call.

nals, produced after right and left denervation, respectively, add in a simple, linear fashion to form the "dee" (Table 2). These findings contrast with previous work on the songs of chaffinches (Nottebohm, 1971, 1972), canaries (Nottebohm and Nottebohm, 1976), and several species of sparrow (Lemon, 1973; Nottebohm and Nottebohm, 1976; Seller, 1979), in which the production of particular acoustic elements was attributed to the independent functioning of one or the other syringeal halves. Instead, the "dee" syllable is produced through a cooperative interaction of both sides of the organ (Nowicki and Capranica, 1986).

Denervating either side of the chickadee's syrinx results in the production of a noisy sound in which is embedded a strong harmonic signal with a fundamental frequency in the range of $1500-2000 \mathrm{~Hz}$, and 2 or 3 higher harmonics. The frequency of this fundamental depends on which side is cut. If the right side is denervated, a spectral component corresponding to component 1 of the intact signal (about $1600 \mathrm{~Hz}$ ) is present with its harmonics. On the other hand, if the left side is denervated, component 2 (about $2000 \mathrm{~Hz}$ ) and its harmonics predominate (Fig. 7). These results suggest that 2 syringeal sources are involved in the production of the "dee"- the oscillator on the left
Table 2. Sum and difference frequencies generated by addition or multiplication of $\mathbf{2}$ harmonic signals, with fundamental frequencies as shown ${ }^{a}$

\begin{tabular}{|c|c|c|c|c|}
\hline \multirow[b]{2}{*}{$\begin{array}{l}\text { Harmonic } \\
\text { relationship }\end{array}$} & \multirow{2}{*}{$\begin{array}{l}\text { Additive } \\
\text { (I inear) } \\
f_{1}=1600 \\
f_{2}=2000 \\
\end{array}$} & \multicolumn{3}{|c|}{$\begin{array}{l}\text { Multiplicative } \\
\text { (Nonlinear) }\end{array}$} \\
\hline & & $\begin{array}{l}f_{1}=1600 \\
f_{2}=2000\end{array}$ & $\begin{array}{l}f_{1}=1400 \\
f_{2}=1800\end{array}$ & $\begin{array}{l}f_{1}=1500 \\
f_{2}=1875\end{array}$ \\
\hline$f_{2}-f_{1}$ & & 400 & 400 & 375 \\
\hline $2 f_{2}-2 f_{1}$ & & 800 & 800 & 750 \\
\hline $3 f_{2}-3 f_{1}$ & & 1200 & $\begin{array}{c}1200 \\
*\end{array}$ & 1125 \\
\hline$f_{\mathrm{i}}$ & 1600 & 1600 & 1400 & 1500 \\
\hline$f_{2}$ & 2000 & 2000 & 1800 & 1875 \\
\hline $2 f_{2}-f_{1}$ & & 2400 & 2200 & 2250 \\
\hline $3 f_{2}-2 f_{1}$ & & 2800 & $\begin{array}{c}2600 \\
*\end{array}$ & 2625 \\
\hline $2 f_{1}$ & 3200 & 3200 & 2800 & 3000 \\
\hline$f_{2}+f_{1}$ & & 3600 & 3200 & 3375 \\
\hline $2 f_{2}$ & 4000 & 4000 & 3600 & 3750 \\
\hline $3 f_{2}-f_{1}$ & & 4400 & $\begin{array}{c}4000 \\
*\end{array}$ & 4125 \\
\hline $3 f_{1}$ & 4800 & 4800 & 4200 & 4500 \\
\hline$f_{2}+2 f_{1}$ & & 5200 & 4600 & 4875 \\
\hline $2 f_{2}+f_{1}$ & & 5600 & 5000 & 5250 \\
\hline $3 f_{2}$ & 6000 & 6000 & $\begin{array}{c}5400 \\
*\end{array}$ & 5625 \\
\hline $4 f_{1}$ & 6400 & 6400 & 5600 & 6000 \\
\hline$f_{2}+3 f_{1}$ & & 6800 & 6000 & 6375 \\
\hline $2 f_{2}+2 f_{1}$ & & 7200 & 6400 & 6750 \\
\hline $3 f_{2}+f_{1}$ & & 7600 & 6800 & 7125 \\
\hline
\end{tabular}

a See text for details. Only values below $8000 \mathrm{~Hz}$ are included. The componen $4 f_{1}$, sometimes observed in postoperative signals, is added for completeness. Asterisks mark irregular frequency intervals in the multiplicative series. All frequencies are in hertz.

side responsible for producing component 1 in intact and rightsectioned birds and the oscillator on the right side responsible for producing component 2 in intact and left-sectioned birds.

\section{Nonlinear model of bilateral syringeal interaction}

A linear summation of the frequency components present in the postoperative recordings of birds after unilateral denervation of the right and left syringeal sides does not result in all the frequencies observed in the spectrum of a normal "dee" syllable (Table 2). That is, a simple superposition of spectra from Figures 4 and 5 , respectively, does not account for the spectral structure observed in Figure $1 B$. We have previously suggestcd a hypothesis (Nowicki and Capranica, 1986), presented in detail below, that accounts for the production of frequency components by an intact bird which are not seen in either of the postoperative conditions. The correspondence between the first 2 spectral components of the preoperative signal and the fundamental frequencies of the postoperative signals, as well as the observation that the frequency interval between all spectral components in the normal signal invariably equals the interval between components 1 and 2, suggests that the spectral components of the intact call arise as heterodyne frequencies (sum and difference frequencies) resulting from a nonlinear coupling between the 2 syringeal sources.

In general, a linear system implies that 2 signals will pass through that system without interaction. Their output is equal to a simple addition of the outputs of each signal by itself, with neither signal affecting the other. The "beating" of 2 signals, 


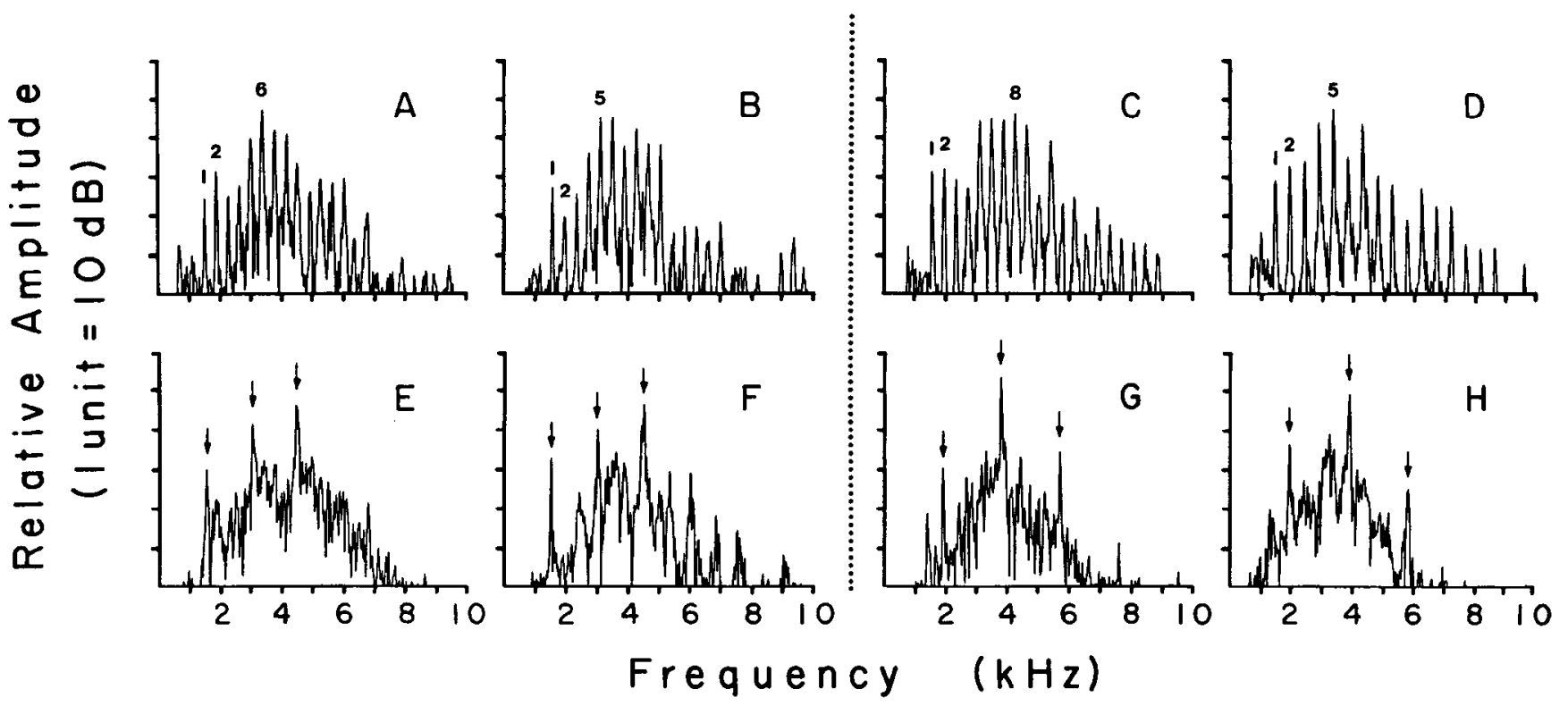

Figure 7. Comparison of pre- and postoperative amplitude spectra for 4 different birds. $A-D$, Preoperative spectra, with frequency components numbered as in Figure $1 B . E, F$, Postoperative spectra following section of the right ts nerve. $G, H$, Postoperative spectra following section of the left ts nerve. Arrows indicate postoperative harmonic components. Each postoperative signal was generated by the same bird responsible for the preoperative signal above it. Values for frequency components (in IIz) are $A, 1=1500,2=1875 ; E$, arrow $=1500$ (bird RY); $B, 1-1525,2=$ $1950 ; F$, arrow $=1500$ (bird GL); $C, 1=1525,2=1925 ; G$, arrow $=1900$ (bird NW); $D, 1=1425,2=1900 ; H$, arrow $=1925$ (bird WP). (Reprinted with permission from Nowicki and Capranica. Copyright 1986 by the AAAS.)

sometimes suggested as the origin of AM-like waveforms in bird sounds (Gaunt et al., 1982; Greenewalt, 1968; Marler, 1969), is an example of a linear phenomenon. In this case, only the frequencies present in the 2 input signals are represented in the output. A nonlinear system, on the other hand, implies that the system's output is dependent on a more complex function of its inputs, and thus that new frequencies are generated. The simplest model function for a nonlinear interaction is multiplication of 2 signals, a process equivalent to amplitude modulation. To appreciate the significance of this operation, consider 2 sinusoidal oscillators:

$$
\begin{aligned}
& v_{1}(t)=A+B \cos f_{1} t \\
& v_{2}(t)=C+D \cos f_{2} t
\end{aligned}
$$

where $A$ and $C$ are constants that represent the unidirectional encrgy flow from each process (i.e., "direct current" terms), $B$ and $D$ are the amplitudes, and $f_{1}$ and $f_{2}$ are the frequencies of the two oscillator sources. (The general expression for a sine wave is of the form, $K \cos 2 \pi f t$. In the above and in all subsequent equations, the $2 \pi$ factor has been omitted for the sake of brevity.) Multiplication of these 2 signals yields

$$
\begin{aligned}
v_{1}(t) \cdot v_{2}(t)= & A C+B C \cos f_{1} t+A D \cos f_{2} t \\
& +B D \cos f_{1} t \cos f_{2} t
\end{aligned}
$$

By use of the trigonometric identity,

$$
\cos x \cdot \cos y=1 / 2 \cos (x+y)+1 / 2 \cos (x-y)
$$

this expression can be expanded to

$$
\begin{aligned}
v_{1}(t) \cdot v_{2}(t)= & A C+B C \cos f_{1} t+A D \cos f_{2} t \\
& +1 / 2 B D \cos \left(f_{2}+f_{1}\right) t+1 / 2 B D \cos \left(f_{2}-f_{1}\right) t
\end{aligned}
$$

Thus, the nonlinear process of multiplication of 2 pure tones yields sum and difference frequencies in the output, as well as the original input, frequencies.

If this same operation is applied in general to 2 periodic signals, each with harmonic overtones, a more extensive set of sum and difference frequencies is obtained. For example, con- sider 2 fundamental sources with higher harmonics (corresponding to the postoperative signals obtained from chickadees after right and left unilateral ts nerve sections):

$$
\begin{aligned}
& v_{1}(t)=A+B_{1} \cos f_{1} t+B_{2} \cos 2 f_{1} t+\cdots+B_{\mathrm{m}} \cos m f_{1} t \\
& v_{2}(t)=C+D_{1} \cos f_{2} t+D_{2} \cos 2 f_{2} t+\cdots+D_{\mathrm{n}} \cos n f_{2} t
\end{aligned}
$$

where $\mathrm{m}$ and $\mathrm{n}$ are integers. Multiplication of these two signals yields the following terms:

$$
\begin{aligned}
v_{1}(t) \cdot v_{2}(t)= & A C+B_{1} C \cos f_{1} t+A D_{1} \cos f_{2} t \\
& +1 / 2 B_{1} D_{1} \cos \left(f_{2}+f_{1}\right) t \\
& +1 / 2 B_{1} D_{1} \cos \left(f_{2}-f_{1}\right) t \\
& +C B_{2} \cos 2 f_{1} t+1 / 2 B_{2} D_{1} \cos \left(f_{2}+2 f_{1}\right) t \\
& +1 / 2 B_{2} D_{1} \cos \left(f_{2}-2 f_{1}\right) t \\
& +A D_{2} \cos 2 f_{2} t+1 / 2 B_{1} D_{2} \cos \left(2 f_{2}+f_{1}\right) t \\
& +1 / 2 B_{1} D_{2} \cos \left(2 f_{1}-f_{1}\right) t+\cdots
\end{aligned}
$$

The general terms of this expression are

$$
\begin{gathered}
C B_{\mathrm{m}} \cos m f_{1} t \\
A D_{\mathrm{n}} \cos n f_{2} t \\
1 / 2 B_{\mathrm{m}} D_{\mathrm{n}} \cos \left(n f_{2}+m f_{1}\right) t \\
1 / 2 B_{\mathrm{m}} D_{\mathrm{n}} \cos \left(n f_{2}-m f_{1}\right) t
\end{gathered}
$$

Thus, in general, multiplication of 2 harmonic series gives rise to a frequency component at each individual harmonic, plus sum and difference frequency components corresponding to each cross-product.

With regard to the "dee" syllable, if $f_{1}=1600 \mathrm{~Hz}$ and $f_{2}=$ $2000 \mathrm{~Hz}$-realistic values for components 1 and 2-then energy appears in a large number of sidebands with a spacing between them of $400 \mathrm{~Hz}$ (Table 2). These spectral components precisely correspond to the spectrum of a normal "dee" syllable, suggesting that the coupling in the chickadee's syrinx involves a nonlinear operation equivalent to mutual amplitude modulation between 2 oscillatory sources, each composed of a single harmonic series (Nowicki and Capranica, 1986).

The most orderly spectral structure, which is also reflected in 


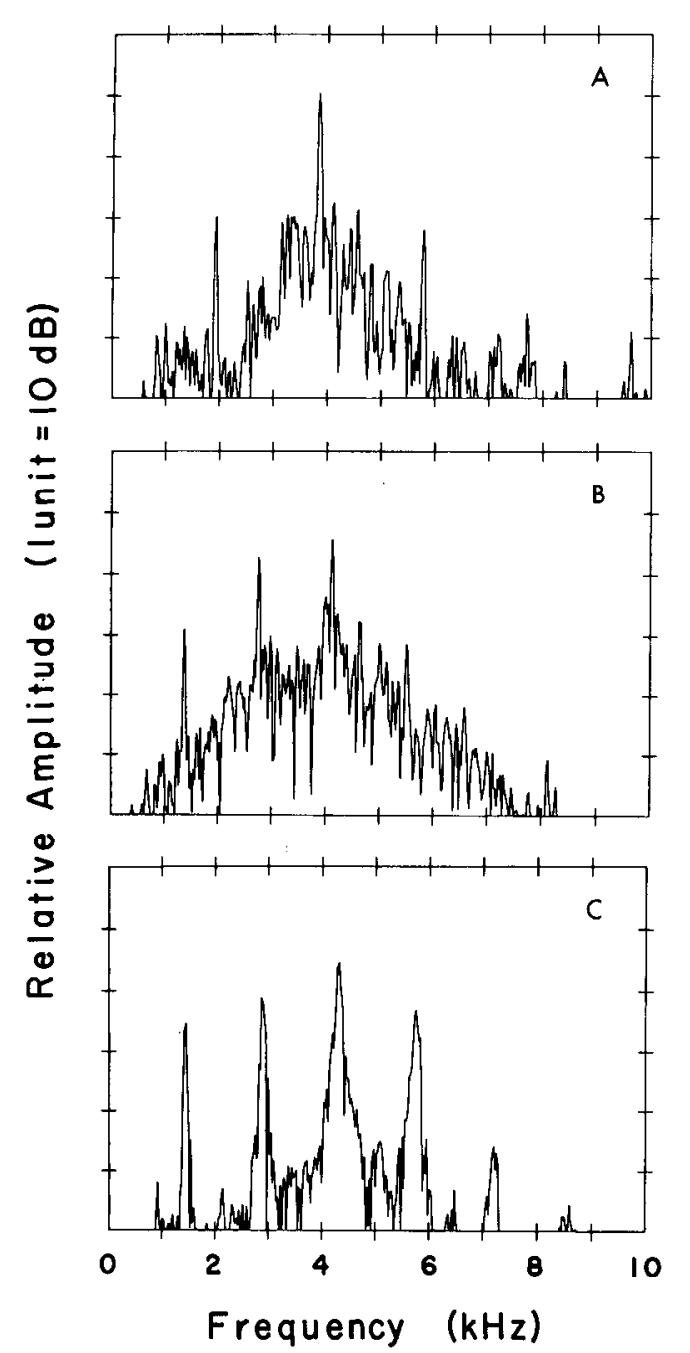

Figure 8. Amplitude spectra of "dee" syllables produced $10 \mathrm{~d}$ after either left $(A$, bird NW) or right $(B, C$, bird GL) ts nerve section, illustrating a decrease in extraneous spectral components. Syllables corresponding to $B$ and $C$ were produced within a few minutes of each other. See text for details.

the most regular periodic envelope of the temporal waveform, occurs when the diffcrence frequency between $f_{1}$ and $f_{2}$ is an integral divisor of the 2 frequencies. In the case where $f_{1}=1600$ $\mathrm{Hz}$ and $f_{2}=2000 \mathrm{~Hz}$, the highest common divisor is $400 \mathrm{~Hz}$ (Table 2). Similarly, if $f_{1}=1500$ and $f_{2}=1875 \mathrm{~Hz}$ (both frequencies being integral multiples of $375 \mathrm{~Hz}$ ), then all the resulting sum and difference frequencies are cvenly spaced at 375 $\mathrm{Hz}$ (Table 2). If, on the other hand, $f_{1}=1400 \mathrm{~Hz}$ and $f_{2}=1800$ $\mathrm{Hz}$, then the nonlinearity yields a series of unevenly spaced cross-products with several $200 \mathrm{~Hz}$ intervals between successive frequency components, most of which are spaced at $400 \mathrm{~Hz}$ intervals (Table 2). Seen in this light, it becomes clear why the sideband structure of the "dee" syllable has been misinterpreted as a single harmonic series with a missing low-frequency fundamental in the range of $350-450 \mathrm{~Hz}$ (Greenewalt, 1968). The most regular, or harmoniclike, spectral structure emerges when the tuning between the 2 oscillators yields a realistic value for this "false" fundamental frequency, a condition observed in a majority $(>66 \%)$ of all "dee" syllables examined (Nowicki and Capranica, 1986).

Although it is theoretically possible to calculate the relative amplitudes of each of the modulation products (equation 3), it is difficult in practice to determine realistic initial amplitude

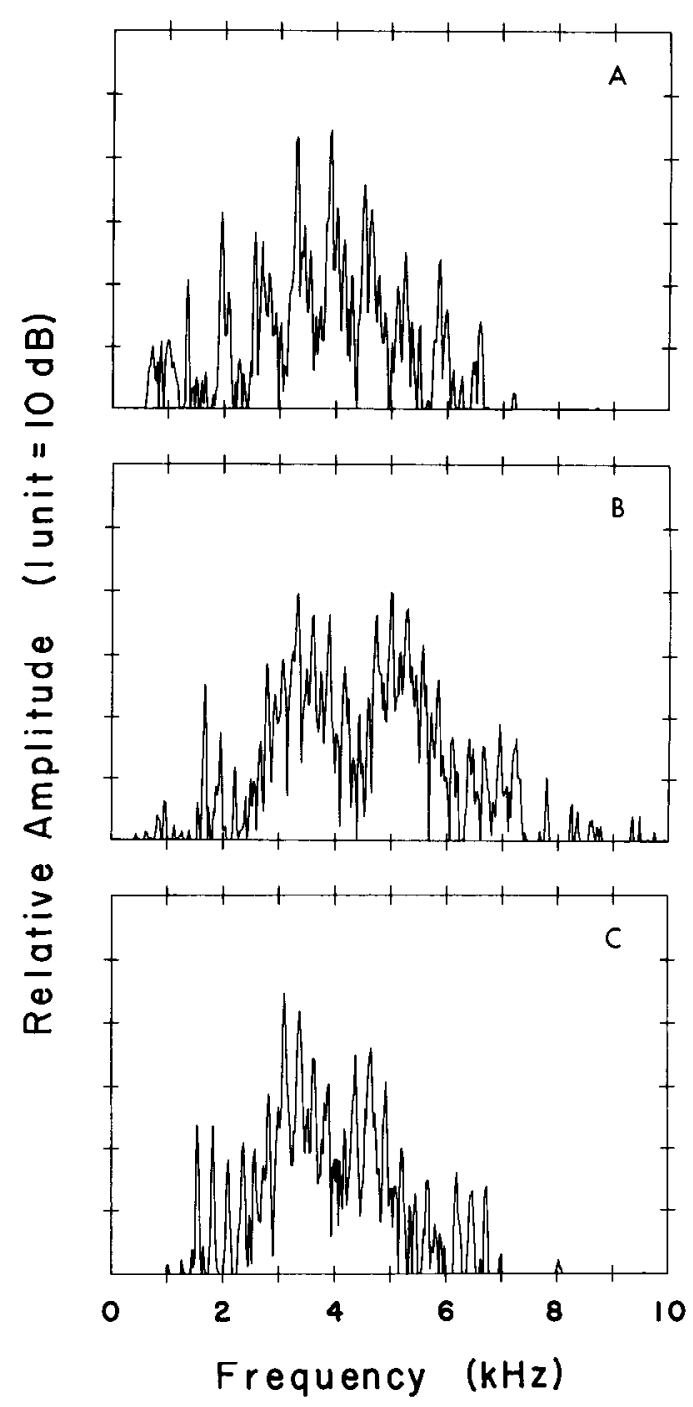

Figure 9. Amplitude spectra of "dee" syllables produced 10 or $11 \mathrm{~d}$ after either left $(A$, bird WP) or right $(B$, bird TE; $C$, bird RY) ts nerve section, illustrating an increase in the appearance of regularly spaced spectral components. See text for details.

values for the harmonics of each oscillator observed in postoperative signals. The amplitudes of these components are highly variable within different signals, even from the same bird. which is likely due to variation in the concomitant broadband noise. Furthermore, even if postoperative signals could provide reliable estimates of harmonic amplitudes, it is not yet possible to know the frequency dependency of the coupling coefficient within the chickadee's syrinx, rendering the calculation of amplitude values misleading.

Nonetheless, all cases of cross-modulation between 2 harmonic oscillators predict energy at the difference frequency $f_{2}-$ $f_{1}$ (Table 2) and at the first 2 multiples of this frequency; yet significant energy is rarely, if ever, observed at these frequencies in normal signals (Figs. 1, 2). It is possible that, just as with the human voice (e.g., Fant, 1960), the amplitudes of the frequency components are ultimately shaped by acoustic resonance properties within the vocal tract. Thus, one might envision a vocal bandpass filter with a center frequency in the range of 3500 $4000 \mathrm{~Hz}$ that effectively selects against the lowest heterodyne components $-\mathrm{a}$ hypothesis supported by 2 observations from the present study. After bilateral nerve section, the spectral properties of the "dee" and wheezing sounds are similar, except that 


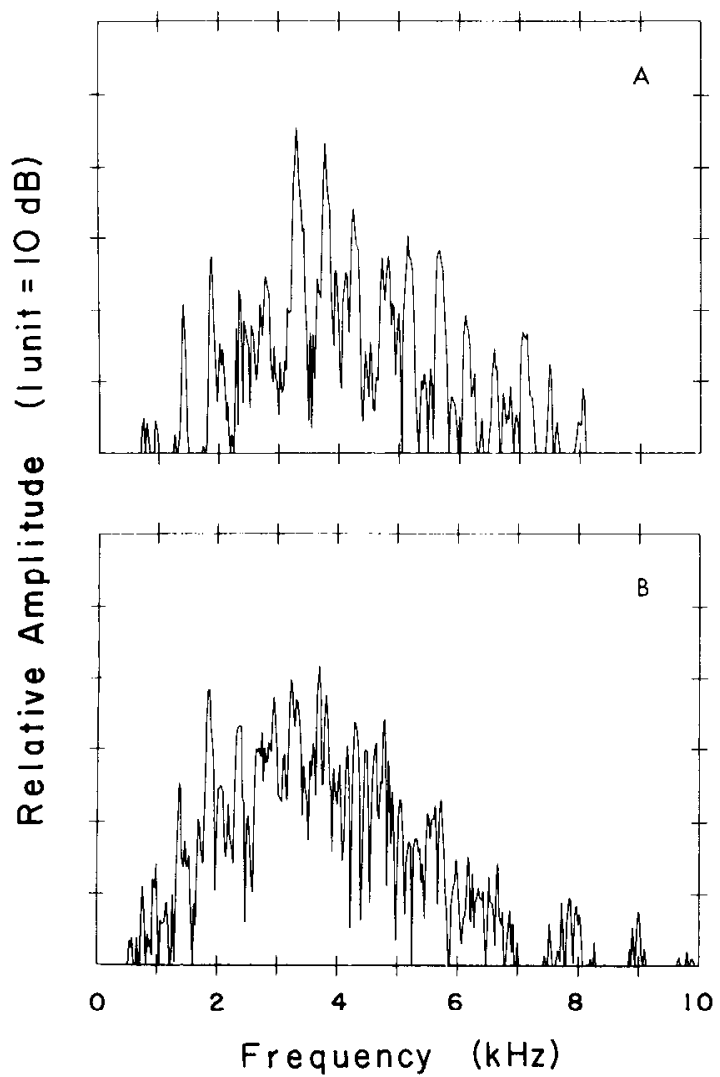

Figure 10. Amplitude spectra of "dee" syllables produced $27 \mathrm{~d}$ after left ts nerve section (bird WP). Syllables corresponding to $A$ and $B$ were produced within a few seconds of each other.

the wheezes contain energy at frequencies almost twice as high as those found in the "dee" (Figs. 11-13). In the absence of neural control of the syringeal musculature, when the oscillators can only be passively excited by airflow, this extreme difference in bandwidth can most easily be accounted for by the presence of a vocal filter that is set independently during vocalization. Similarly, the bandwidths of bilateral postoperative introductory syllables and "dee" syllables differ to the same degree as in the normal signals, even though the normal spectral structure of both syllables is lost completely (compare Fig. 12 with Fig. $1 A$ ). Experiments in which birds were recorded while singing in helium air have confirmed the existence of a vocal resonance filter in several species, including chickadees (S. Nowicki, unpublished observations).

\section{Neural control and acoustic feedback in the production of the "dee"}

The operation of the oscillators responsible for generating the "dee" syllable is not completely dependent on the presence of intact innervation. Although the fundamental frequency component that presumably arises from the oscillator on the denervated side is reduced in amplitude and becomes less stable in frequency, it is nonetheless often apparent. Especially in the case of a left ts section, the lower-frequency oscillator (corresponding to component 1) rarely drops out of the signal completely (Fig. 5). Even after bilateral denervation, the characteristic signals of components 1 and 2 are sometimes observed both when a bird is attempting to call (Fig. 13C) and when a bird is only forccfully brcathing (Fig. $11 \mathrm{~A}$ ). These results suggest that the 2 oscillators are capable of being passively induced into a reasonably stable oscillation, each at its own natural frequency. The left syringeal half in most oscines is slightly larger than the right (Nottebohm, 1980). The natural frequency of vibration of structures on the left side is therefore expected to be lower in frequency, as is observed here.

The coupling between the 2 syringeal oscillators must involve both active and passive properties. Cutting either ts nerve partially disables the coupling, as evidenced by the loss of a harmoniclike spectral structure, even in the presence of strong signals from both oscillators (Figs. 4, 5, 7; see especially Fig. 6A). This result suggests that the coupling mechanism is influenced by neural control and that the control is bilateral. The coupling is not always completely disrupted, however, under these conditions. Spectral components spaced at the difference frequency between components 1 and 2 still occur in many postoperative signals (e.g., Fig. $5 \mathrm{C}$ ), especially in proximity to the harmonics of the stronger postoperative oscillator. Although not consistently present in postoperative signals, when they do appear these spectral components are predicted as sum or difference frequencies generated by the multiplication of a signal with 3 harmonics (presumably produced by the remaining intact side) and a signal with energy only at the fundamental frequency (presumably produced by the denervated side). Thus, it is likely that the nonlinear coupling arises from a passive physical interaction between the 2 syringeal sides that is either activated or regulated by bilateral neural control.

Ten days after unilateral nerve section, the voice assumed to arise from the denervated side is occasionally silenced completely (Fig. 8). If both voices remain active, however, the number of sum and difference frequency components increases (Fig. 9), possibly because the bird has learned to compensate and control the coupling with only unilateral innervation. It is unlikely that these changes are due to nerve regeneration in so short a time. All birds reoperated upon at this stage showed a small neuroma proximal to the previous cut, but no obvious
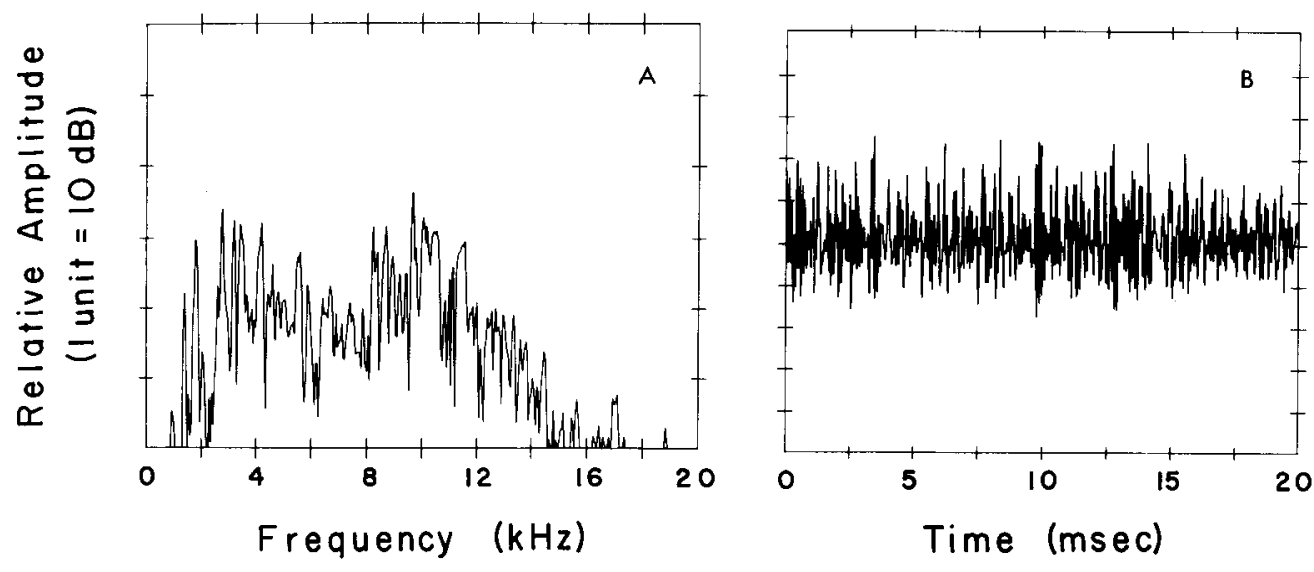

Figure 11. A, Amplitude spectrum of wheezing sound made when an excited bird breathed after bilateral ts nerve section (bird RY). $B$, Waveform corresponding to spectral section in $A$. Note that the frequency scale of $A$ is twice that of previously shown amplitude spectra, while the time scale of $B$ is one-half that of previously shown waveforms. 


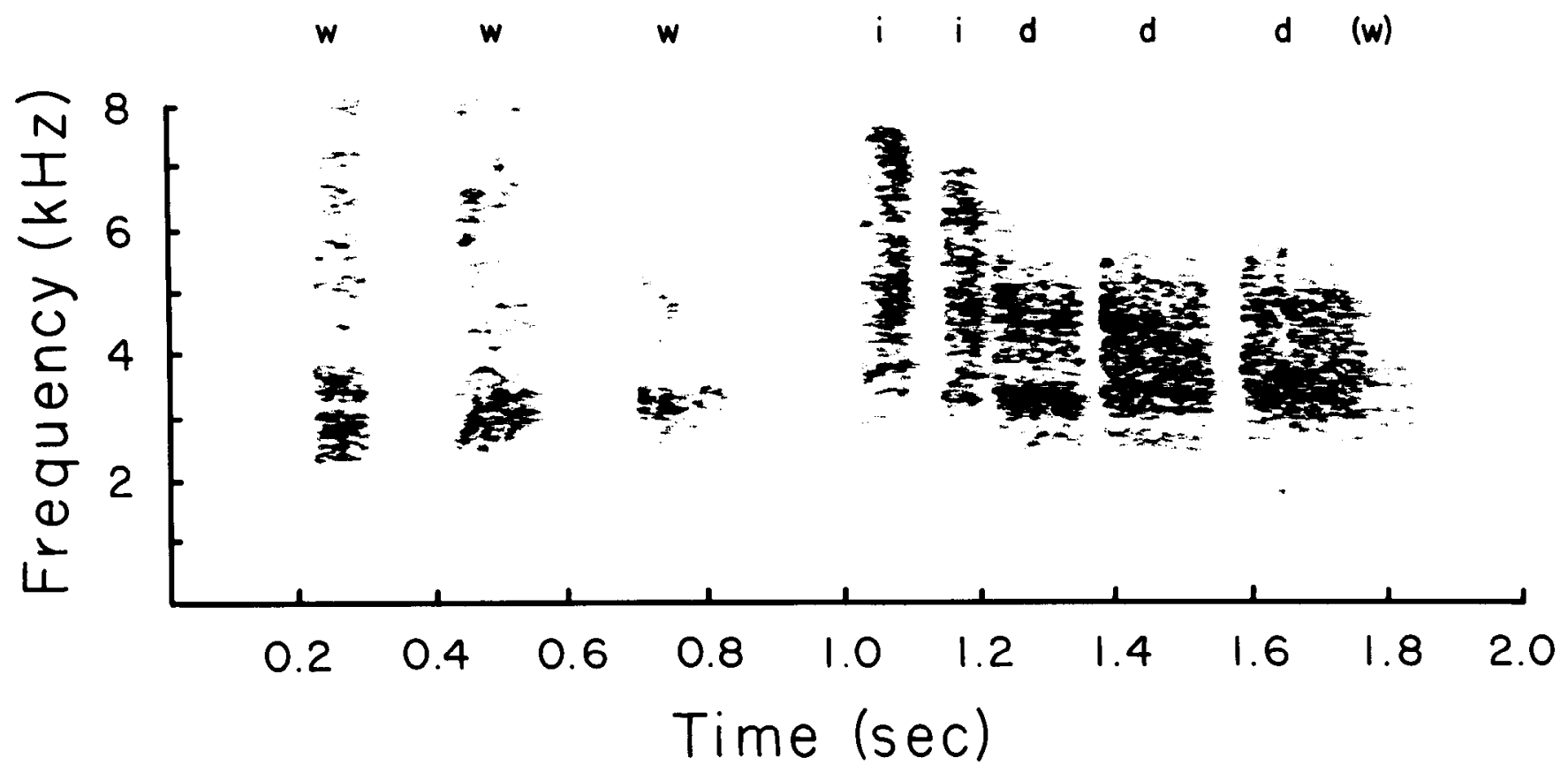

Figure 12. Narrow-band $(45 \mathrm{~Hz})$ sonagram of a "chick-a-dee" call made $13 \mathrm{~d}$ after bilateral ts nerve section, including 2 introductory syllables $(i)$ and 3 "dee" syllables $(d)$. Also shown are 3 wheezes $(w)$ resulting from excited breathing preceding the call, and 1 wheeze immediately following the last "dee" syllable. The wheezes are of much lower amplitude than the call, hence their extended bandwidth is less apparent, given the limited dynamic range of the sonagram display.

processes extended beyond this point. Longer-term recovery leads to even better production of a harmonic-like signal (e.g., Fig. 10A). These long-term improvements may be due to increased practice with unilateral control or actual nerve regeneration, although it is not possible to assess carefully the latter possibility with these limited data.

If both nerves are cut, signals from the oscillators may still be observed, but coupling, as seen in the appearance of sum and difference frequencies, is virtually eliminated (Figs. 11, 13). The bird has totally lost control over the mechanism of coupling, as well as over the oscillators. A comparison of the 1 bird that remained vocal for an extended period after bilateral denervation with 2 birds recorded 2 d postoperatively reveals no evidence of short-term recovery of coupling after $13 \mathrm{~d}$ (contrast Fig. $13 A$ with $B$ and $C$ ). Presumably, then, a bird requires at least unilateral innervation to compensate and achieve any sort of bilateral syringeal interaction. The above bird was capable of occasionally producing a highly structured syllable $31 \mathrm{~d}$ after bilateral denervation (Fig. 14A). We do not know whether this result was due to functional neural regeneration of 1 or both syringeal sides. The fact that such signals were rare and that most sounds produced at this time were very noisy (Fig. 14B) suggests that this bird was still compensating for extreme deficiencies in its control over the coupling mechanism.

Chickadees do compensate for vocal deficiencies over periods of time far too short to allow for any neural regeneration, suggesting that auditory feedback may play an important role in the motor control of phonation in adult chickadees. This hypothesis is in contrast to previous work suggesting that once an adult bird has learned a song, it executes the motor patterns underlying this phonatory behavior without reference to auditory feedback, as evidenced by the minimal impact that deafening of the adults of most species has on the structure of their songs (Konishi, 1965; Nottebohm, 1968). The deafening of adult canaries has been shown to have a more significant effect on their vocal behavior (Nottebohm et al., 1976), and this difference may be due to this species' extension of vocal plasticity into adulthood (Nottebohm and Nottebohm, 1978). The ability to almost immediately compensate for vocal disabilities, however, seems so far to be unique to chickadees.

\section{The physical bases of syringeal coupling}

The mechanisms through which acoustic vibrations arise and are controlled in the oscine syrinx are not well understood. The most widely accepted view, originally formulated by Greenewalt (1968), holds that the medial tympaniform membranes (MTM) on the rostral portions of the medial bronchial walls are induced to vibrate through Bernoulli forces created by pulmonary air rushing past them (see also Brackenbury, 1982; Gaunt and Gaunt, 1985; Gaunt and Wells, 1973; Nottebohm, 1975). The syringeal musculature is believed to control the position and tension of the MTM on each syringeal side and thus to superimpose both frequency and amplitude modulations on the membrane's vibration (Greenewalt, 1968). Greenewalt (1968) also hypothesized that bird sounds rich in harmonic content result from a condition in which the tension on the MTM is sufficiently low to allow the membrane to be driven into nonsinusoidal motion.

Greenewalt's (1968) model of MTM oscillation (as well as other alternative models, e.g., Gaunt et al,, 1982; Klatt and Stefanski, 1974) is based on acoustic inference. That is, the model was deduced from the temporal and spectral signal characteristics of birdsong, and has not been experimentally tested. In fact, no direct or indirect measurements of syringeal action during phonation have yet been made. Given this fact and the theoretical problems associated with the proposed models (Casey and Gaunt, 1985; Gaunt and Wells, 1973; Nowicki, 1985), it is fair to conclude that oscine syringeal mechanics are still a matter of speculation.

In the absence of adequate data concerning the induction and control of a single syringeal source, it is possible only to speculate as to the physical processes responsible for coupling between 2 such sources. It is conceivable that the observed nonlinearity occurs in the airstream of the vocal tract anterior to the sourccs of oscillation. The configuration of the tract may be altered in 


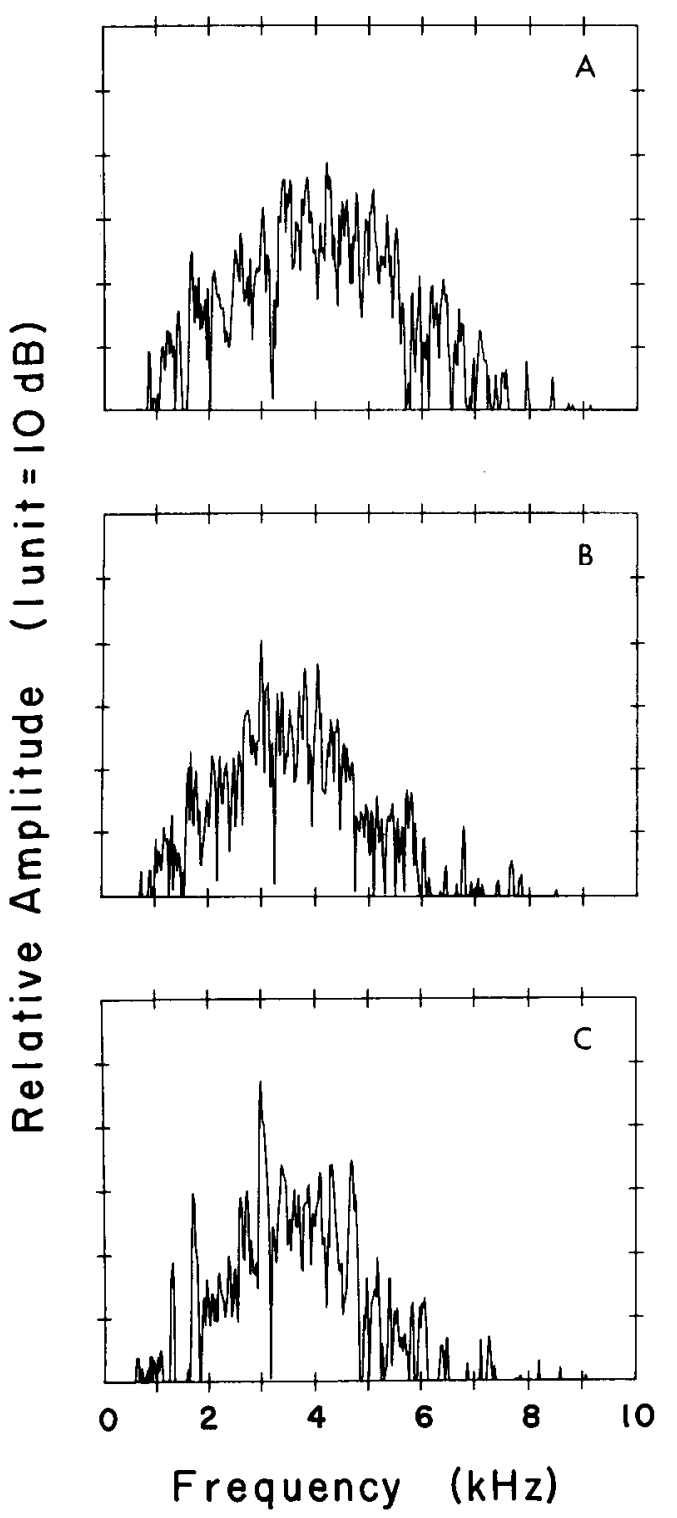

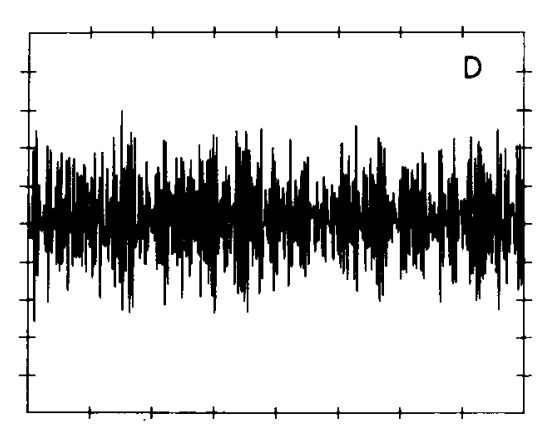
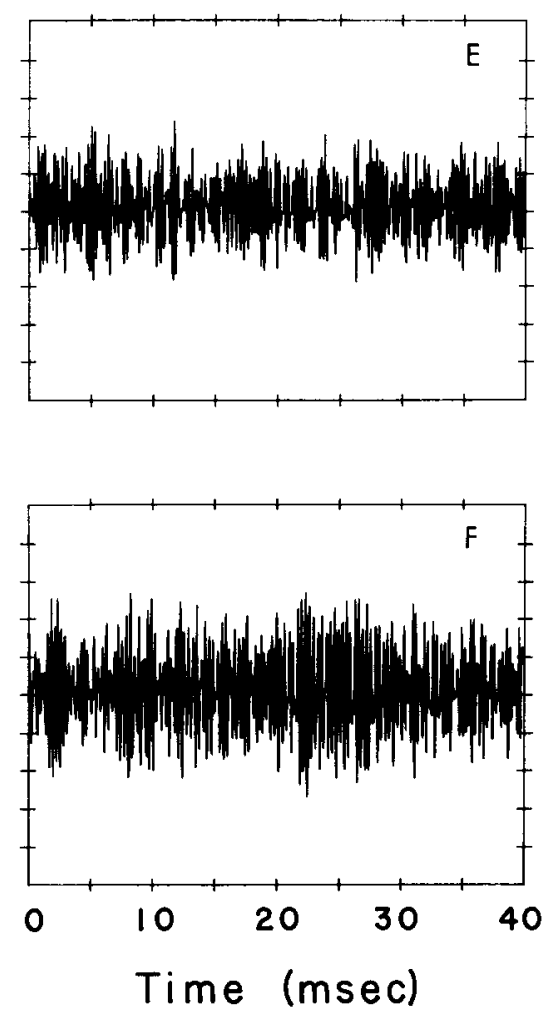

Figure 13. $A-C$, Amplitude spectra of "dee" syllables produced 2 or $13 \mathrm{~d}$ after bilateral ts nerve section $(A$, bird NW, $13 \mathrm{~d} ; B, C$, bird TE, $2 \mathrm{~d}) . D-F$, Temporal waveforms corresponding to spectral sections $A-C$, respectively. Syllables illustrated in $B$ and $C$ were produced within seconds of each other. such a way as to cause turbulence, but it is difficult to imagine how this kind of interaction could give rise to the extraordinarily noise-free spectra observed in normal birds.

Nonlinearity is more likely to result from a direct physical interaction between the 2 oscillators. Several types of connection between the sources are possible. For example, pressure feedback may provide a mechanism through which the oscillators modulate each other (Nowicki and Capranica, 1986). If this feedback is transmitted within the vocal tract, a significant amount of acoustic energy from each oscillator must reach the contralateral bronchus. Although precisc measurcments have not been made, the acoustic impedance of the trachea is probably lower than that of the bronchi, making it unlikely that much acoustic energy from 1 side could reflect down the contralateral bronchus. A more plausible transmission pathway for pressure coupling between the 2 syringeal sides is the air spacc of the interclavicular air sac. This air sac, which ramifies between the two MTMs, could provide a direct pressure connection isolated from the tracheobronchial air stream. Finally, it is possible that some form of structural coupling might exist (Nowicki and Capranica, 1986). The pessulus, for example, is a cartilaginous tissue connecting the medial walls of the bronchi and is thus situated in a position that would allow it to transmit energy between the two syringeal halves.

Whatever the mechanism of coupling, it likely involves some passive physical principle that is enhanced, or turned on and off, through neural control. In addition to the "dee" syllable, the chickadee produces a variety of pure-tone, or whistlelike, sounds more typical of oscine vocalizations, including the introductory syllables of the normal "chick-a-dee" call (Fig. $1 A$ ). Thus, the chickadee's syrinx must be capable of assuming at least 2 different states, 1 in which the 2 acoustic sources are coupled and 1 in which they arc not. If the coupling is activated by a configurational change mediated by the syringeal musculature, it is possible a bird may learn to compensate for loss of control on one side (Fig. 9) by exaggerating configurational differences on the contralateral side. The resulting configuration may be less stable, as is suggested by the appcarance of very noisy spectra intermingled with spectra having well-defined components in the same series of vocalizations (Fig. 10).

The tuning of the 2 oscillators is undoubtedly also important for achieving the orderly spectral structure of a normal coupled signal. It is possible that the nonlinearity is efficiently excited only by narrowly tuned best frequencies of both oscillators, or 


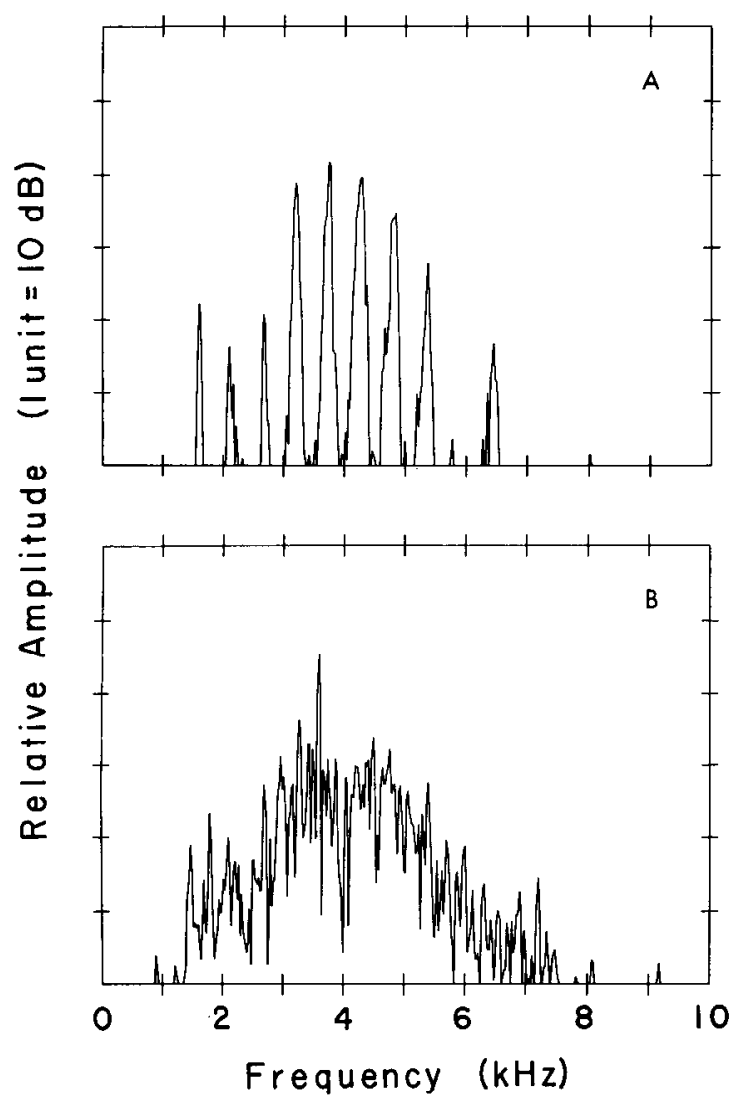

Figure 14. Amplitude spectra of 2 "dee" syllables produced $31 \mathrm{~d}$ after bilateral ts nerve section (bird NW). The syllables corresponding to $A$ and $B$ were produced within a few minutes of each other.

by the tuning of the difference frequency between the 2 oscillators (e.g., Table 2). The bird may compensate for loss of control of 1 oscillator by simply tuning the intact oscillator to an appropriate relative frequency. The inability of the bird to perfectly track the variable frequency of the denervated oscillator may account for the sporadic production of "noisy" and "clean" spectra by the same bird. In this case, the apparent control of the coupling mechanism would in fact be only an epiphenomenon of the control exerted over the tuning of the 2 syringeal oscillators.

\section{Lateralization of syringeal function and the "two-voice theory" reexamined}

Sounds previously examined in work on the neural lateralization of vocal control in oscines have largely been relatively pure tones with slow modulations, which are presumed to result from the action of only 1 syringeal source. If such sounds are produced by the oscillator corresponding to the side of the organ that is denervated, then those notes drop out entirely from the sequence of acoustic elements comprising the song or are replaced by unstructured noise (Lemon, 1973; Nottebohm, 1971; Nottebohm and Nottebohm, 1976; for a review, see Arnold and Bottjer, 1985). Some of the chaffinch calls examined by Nottebohm (1972) included 2 nonharmonic acoustic elements overlapping in time. In such cases, unilateral section of the hypoglossal nerve caused one or the other of these elements to drop out, leaving the other element unchanged. Nottebohm (1972) argued that these 2 elements must be produced simultaneously and independently by the 2 syringeal oscillators.

The 2 halves of the chickadee's syrinx clearly do not function independently in the production of the "dee" syllable, as is evidenced by the fact that the frequency components obtained after right and left denervation do not add to produce the normal syllable. The failure of simple additivity by itself does not preclude the independent operation of 2 sources during normal vocalization. Nottebohm (e.g., 1971; Nottebohm and Nottebohm, 1976), for example, described unmodulated sounds and noise that replaced certain acoustic elements after unilateral denervation. Because these new sounds appeared only after surgery, the postoperative vocalizations cannot be said to have simply added, strictly speaking, to yield the normal vocalization. But in each of these cases the extraneous acoustic material was attributable to the uncontrolled action of the denervated syringcal sidc. If thesc noisy or uncontrolled elements are deleted from the analysis, then the 2 postoperative signals did add to give the preoperative signal. Such is not the case in the present

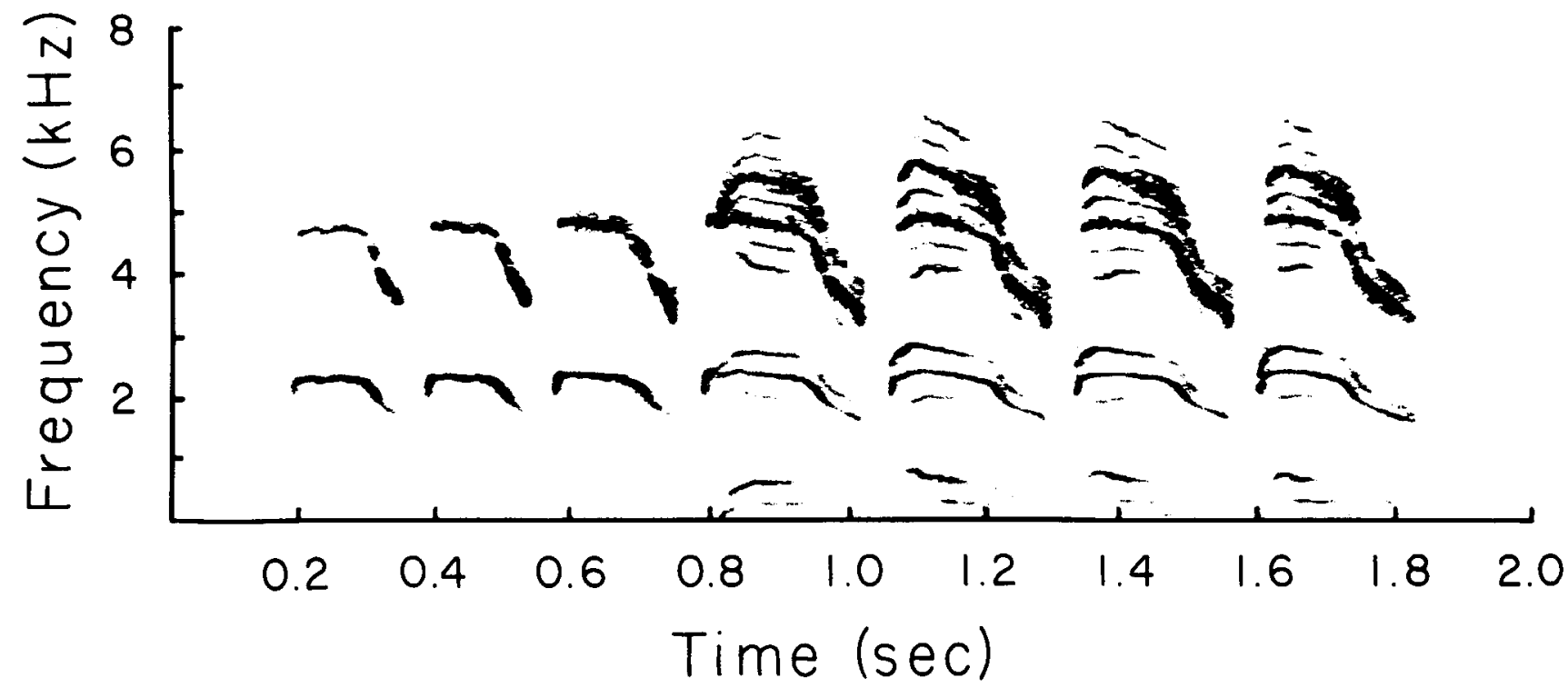

Figure 15. Narrow-band $(45 \mathrm{~Hz})$ sonagram of a song produced by a song sparrow that developed atypical phonology during laboratory studies of vocal learning (P. Marler and S. Peters, unpublished observations). Note that the last 4 acoustic units are composed of simple harmonic series identical to the first 3 units, except for the appearance of components resembling modulation products clustered around the dominant harmonic components. 
analysis, where a simple addition of postoperative frequency components (after excluding noise) yields less than the entire preoperative signal (Table 2). The additional frequencies seen in the sounds of intact animals can only be accounted for by a nonlinear interaction between the 2 sound sources.

Since the acoustic structure of the "dee" syllable is atypical of oscine vocalizations, it is not surprising that the action of the syrinx during its production differs from that suggested for more typical "pure-tone" songs. It is also possible, however, that previously reported cases of complex sounds in the vocal repertoires of other species being replaced by "noise" after unilateral tracheosyringealis section in fact represent sounds in which both syringeal halves cooperate in some fashion, perhaps similar to the chickadee case. Earlier studies have relied solely on sonagraphic analysis, and such data are clearly not sufficiently accurate to specify precisely the spectral characteristics of a postoperative signal (contrast Fig. 3, $A$ and $B$, with Figs. 4 and 5, respectively).

Is the bilateral syringeal coupling described here unique to black-capped chickadees? A preliminary analysis of unilateral syringeal denervation experiments in the mountain chickadee (Parus gambeli) indicates that a similar bilateral syringeal interaction is involved in the phonation of that species as well ( $S$. Nowicki, unpublished obscrvations). This result is expected, given the close taxonomic relationship between the 2 species and the acoustic similarities in their vocalizations. More remarkable is the finding that the song sparrow (Melospiza melodia; Emberizidae) might also employ some form of heterodyning between 2 oscillators in the production of ccrtain unusual song syllables (P. Marler, S. Peters, and S. Nowicki, unpublished observations). Sparrows that do not properly learn species-typical phonology, either by chance or by experimental design, often produce broadband sounds deviating from more normal puretone signals (P. Marler and S. Peters, unpublished observations). In some cases the spectra of these atypical sounds strongly resemble a series of modulation products clustered around the components of a harmonic series (e.g., Fig. 15), similar to those observed in chickadees after short-term recovery from unilateral denervation. We predict that the capacity, at least, for some form of bilateral syringeal interaction may be a ubiquitous feature of the oscine syrinx.

Other investigators have begun to question the universality of lateralization of syringeal function on independent grounds. McCasland (1983) and Konishi $(1984,1985)$ found that disabling 1 side of the syrinx of canaries by physically plugging the bronchus yields different vocal results than those obtained by disabling the same side by unilateral denervation. Specifically, no syllables drop out of the song completely after bronchusplugging. Rather, different syllables are subjected to different degrees of distortion after such a procedure, leading these investigators to suggest that both syringeal sides are involved in the production of every phonological unit. As with denervation experiments, the physiological interpretation of bronchus-plugging is clouded by the paucity of information concerning the induction and control of acoustic oscillation in the syrinx (Arnold and Bottjer, 1985). Regardless of this problem, the simplest interpretation of the original syringeal denervation experiments (e.g., Nottebohm, 1971, 1972, 1980) should be reevaluated. While it is likely that the oscine syrinx is sometimes capable of simultaneously producing 2 independent sounds under separate neural control, previous statements of functional lateralization and the "two-voice theory" may encompass only a subset of the syrinx's true versatility as a sound-producing organ.

\section{References}

Arnold, A. P. (1982) Neural control of passerine song. In Acoustic Communication in Birds, Vol. 1, D. E. Kroodsma and E. H. Miller, eds., pp. 75-94, Academic, New York.
Arnold, A. P., and S. W. Bottjer (1985) Cerebral lateralization in birds. In Cerebral Lateralization in Nonhuman Species, S. D. Glick, ed., pp. 11-39, Academic, New York.

Borror, D. J., and C. R. Reese (1956) Vocal gymnastics in wood thrush songs. Ohio J. Sci. 56: 177-182.

Brackenbury, J. H. (1982) The structural basis of voice production and its relationship to sound characteristics. In Acoustic Communication in Birds, Vol. 1, D. E. Kroodsma and E. H. Miller, eds., pp. 53-74, Academic, New York.

Casey, R. M., and A. S. Gaunt (1985) Theoretical models of the avian syrinx. J. Theor. Biol. 116:45-64.

Fant, G. (1960) Acoustic Theory of Speech Production, Mouton, The Hague.

Gaunt, A. S., and S. L. L. Gaunt (1985) Syringeal structure and avian phonation. In Current Ornithology, Vol. 2, R. F. Johnston, ed., pp. 213-245, Plenum, New York.

Gaunt, A. S., and M. K. Wells (1973) Models of syringeal mechanics. Am. Zool. 13: 1227-1247.

Gaunt, A. S., S. L. L. Gaunt, and R. M. Casey (1982) Syringeal mechanics reassessed: Evidence from Streptopelia. Auk 99: 474-494.

Greenewalt, C. II. (1968) Bird Song: Acoustics and Physiology, Smithsonian, Washington, DC.

Häcker, V. (1900) Der Gesang der Vögel, seine anatomischen und biologischen Grundlagen, Gustav Fischer, Jena, GDR.

Klatt, D. H., and R. A. Stefanski (1974) How does the mynah bird imitate speech? J. Acoust. Soc. Am. 55: 822-832.

Konishi, M. (1965) The role of auditory feedback in the control of vocalization in the white-crowned sparrow. $Z$. Tierpsychol. 22:770783.

Konishi, M. (1984) A logical basis for single-neuron study of learning in complex neural systems. In The Biology of Learning, P. Marler and H. S. Terrace, eds., pp. 311-324 (Dahlem Konferenzen 1984), Springer, Berlin.

Konishi, M. (1985) Birdsong: From behavior to neuron. Annu. Rev. Neurosci. 8: 125-170.

Lemon, R. E. (1973) Nervous control of the syrinx in the whitethroated sparrow (Zonotrichia albicollis). J. Zool. (Lond.) 171: 131140.

Mammen, D. L., and S. Nowicki (1981) Individual differences and within-flock convergence in chickadee calls. Behav. Ecol. Sociobiol. 9: $179-186$.

Marler, P. (1969) Tonal quality of bird songs. In Bird Vocalizations, R. A. Hinde, ed., pp. 5-18, Cambridge U. P., Cambridge, IJK.

McCasland, J. S. (1983) Neuronal control of bird song production. Ph.D. dissertation, California Institute of Technology.

Nottebohm, F. (1968) Auditory experience and song development in the chaffinch, Fringilla coelebs. Ibis 110: 549-568.

Nottebohm, F. (1971) Neural lateralization of vocal control in a passerine bird. I. Song. J. Exp. Zool. 177: 229-262.

Nottebohm, F. (1972) Neural lateralization of vocal control in a passerine bird. II. Subsong, calls, and a theory of vocal learning. J. Exp. Zool. 179: 35-49.

Nottebohm, F. (1975) Vocal behavior in birds. In Avian Biology, Vol. 5, D. S. Farner and J. R. King, eds., pp. 287-332, Academic, New York.

Nottebohm, F. (1977) Asymmetries in neural control of vocalization in the canary. In Lateralization of the Nervous System. S. Harnad, R. W. Doty, L. Godstein, J. Jaynes, and G. Krauthamer, eds., pp. 2344, Academic, New York.

Nottebohm, F. (1980) Brain pathways for vocal learning in birds: A review of the first 10 years. Prog. Psychobiol. Physiol. Psychol. 9: 85-124.

Nottebohm, F., and M. E. Nottebohm (1976) Left hypoglossal dominance in the control of canary and white-crowned sparrow song. $J$. Comp. Physiol. 108A: 171-192.

Nottebohm, F., and M. E. Nottebohm (1978) Relationship between song repertoire and age in the canary, Serinus canarius. Z. Tierpsychol. 46: 298-305.

Nottebohm, F., T. M. Stokes, and C. Leonard (1976) Central control of song in the canary, Serinus canarius. J. Comp. Neurol. 165:457486.

Nowicki, S. (1983) Flock-specific recognition of chickadee calls. Behav. Ecol. Sociobiol. 12: 317-320.

Nowicki, S. (1985) The call of the black-capped chickadee: Structure, function, and production of a complex bird sound. Ph.D. dissertation, Cornell University. 
Nowicki, S., and R. R. Capranica (1986) Bilateral syringeal interaction in the production of an oscine bird sound. Science 231: 1297-1299.

Potter, R. K., G. A. Kopp, and H. C. Green (1947) Visible Speech, Van Nostrand, Princeton, NJ.
Savart, F. (1826) Memoire sur la voix des oiseaux. Ann. Chim. Phys. 32: $5-24$.

Seller, T. J. (1979) Unilateral nervous control of the syrinx in Java sparrows (Padda oryzivora). J. Comp. Physiol. 129A: 281-288. 